Research Article

\title{
The Numerical Analysis for Parametric Resonance of Multicable System considering Interaction between Adjacent Beam Portions
}

\author{
Kefan Chen, ${ }^{1}$ Shuanhai He $\mathbb{D}^{1,2}$ Yifan Song ${ }^{1 D},{ }^{1,2}$ Linming $W u,{ }^{1}$ \\ Kang Wang, ${ }^{1}$ and Hanhao Zhang ${ }^{1}{ }^{1}$ \\ ${ }^{1}$ School of Highway, Chang'an University, Xi'an 610064, China \\ ${ }^{2}$ Key Laboratory of Old Bridge Detection and Reinforcement Technology of Ministry of Transport, Chang'an University, \\ Xi'an 610064, China \\ Correspondence should be addressed to Shuanhai He; heshai@chd.edu.cn
}

Received 12 August 2021; Accepted 5 October 2021; Published 3 November 2021

Academic Editor: Sami El-Borgi

Copyright (c) 2021 Kefan Chen et al. This is an open access article distributed under the Creative Commons Attribution License, which permits unrestricted use, distribution, and reproduction in any medium, provided the original work is properly cited.

The investigation aims to propose a refined model to analyze the parametric resonance under multicable systems such as cablestayed bridges. Considering the interaction between the adjacent beam portions, the shear difference is applied to modify the vibration equations derived from the multi-degree-of-freedom stiffness method. Furthermore, the difference method is adopted to make the equations more accessible for numerical analysis. The comparison results indicate that the refined model exhibits the key character of parametric resonance and also further verified the simulation methods. The consequences show that the cable will resonate at the fundamental frequency under the support excitation. In particular, when resonance occurs, most of the energy in the subsystem is transferred to the cable, resulting in the resonance amplitude of the beam portion being weakened to some certain extent. Moreover, the global resonance will have a sufficient excitation on the local resonance only when the resonance condition is satisfied.

\section{Introduction}

Cable-stayed bridges become popular especially in the bridge design of crossing valleys and wide rivers. These structures continually increase the span length in the last decades. In the same manner, they become lighter and more flexible, thus developing into more sensitive to parametric excitation by wind, rain, or car traffic. On some occasions, cables have been excited to severe oscillations even in the small initial response of the bridge beam or tower [1]. So far, it has been observed in numerous engineering practice cases that the cable's lateral maximum amplitude exceeds half a meter, seriously affecting the safe operation of the bridges [2-5].

A few researchers try to explain the causes of the severe oscillations: during one cycle of transverse motion, a coupling resonance occurs between the cable and the beam. The energy conversion between the vibration components leads to the "beat" characteristic of the cable vibration $[6,7]$. To study the occurrence mechanism of parametric resonance, an intensive investigation of the static and dynamic theories of cable structures was conducted [8]. The cable and beam were simplified to lumped mass blocks to investigate the parametric resonance by numerical analysis methods [9]. Through the methods of the multiple scales or finite element, more refined models of the cable-beam system considering the $\lambda$ value which affects the sag of the stay cable were proposed in little research. The sensitivity of parameters including cable force, tensile stiffness, and the mass ratio of the cable to other components has also been discussed [10-15]. The characteristic of parametric resonance was investigated in terms of the data from actual observations and experiments to provide a new perspective of damping technique for stayed cables [16-19].

Ample research studies have concluded that cable is excited to parametric resonance by main beam or tower. El Ouni et al. observed the phenomenon of structural dynamic instability when a local (cable) and a global (structure) mode 
were coupled through the analysis of finite element or experiment, and the effect of amplitude of excitation as well as the active damping of the bridge on the steady-state response of the stay cable was studied numerically and experimentally [20]. The safety of the bridged traffic and pedestrians will be gravely threatened once this severe oscillation occurs obviously. Compared with the numerical results and the measurements on Guadiana Bridge, the interaction mechanism of the cable-deck dynamic stimulated by two internal resonant modes was regarded as the most critical excitation source for the stay cables exhibiting severe oscillations [21]. To study the dynamic behaviors of the cable-supported bridges, researchers proposed a linear multicable-stayed beam model and applied a linear multicable-stayed beam model of different impact factors $[22,23]$. According to the investigation of a refined finite element model, the leading cause of the global-local resonance is further proved to be that the equations and the plane motion boundary condition of the simplified model are showing quadratic and cubic nonlinearity [24]. It is remarkably difficult to carry out the whole-process response time analysis of the whole structure in most finite element software. To obtain more comparable results, the finite element model is required to divide into a large number of elements [25]. Many researchers presented several deep investigations in the refined research of single cable or cable-beam subsystem, focusing on the sensitivity of parameters, vibration control, or different analysis approaches [26-32]. Others provided the research in checking the frequency or modes of one single component instead of simulating the real-time displacement response for global resonance [33-38]. However, the interaction between beam portions in the multicable structures, such as cable-stayed bridges, cannot be reflected by analyzing a single cable model. Additionally, the indirect coupling effect of cables through the bridge deck cannot be ignored [39]. There is still a lot of work waiting to be carried out in the theory and research of nonlinear dynamics modeling of large-scale cable-stayed bridge systems [40].

This paper proposes a refined model to analyze the mechanism of the parametric resonance occurring on cablestayed bridges. The single beam of a cable-stayed bridge is divided into a few independent portions according to the anchorage position of each cable. The vibration equations of the global resonance system are derived from the stiffness method. Moreover, the shear difference is applied to simulate the interaction between adjacent discrete beam portions. The vibration equations of the global resonance are also modified by the difference method to make the equations more accessible to numerical analysis. Based on this, the interaction between adjacent beam portions is deeply discussed.

\section{The Model and Vibration Equations of the Multicable System}

To highlight the research emphasis, the simplified model of a floating cable-stayed bridge is established, as shown in Figure 1.

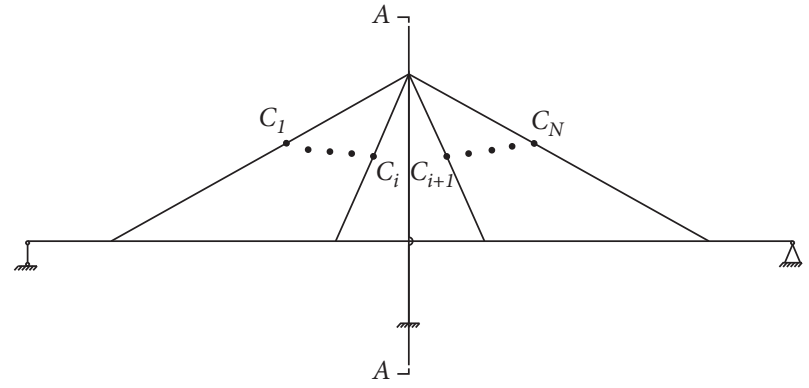

Figure 1: The simplified model for cable-stayed bridges.

As can be referenced from the Virlogeux [41], two lumped mass blocks simplified from one single beam and the anchorage cable were presented to study the mechanism of the parametric vibration. Zhan and Zhong [9] and Zhang et al. [42] also took this simplified approach to study the related phenomena. Following this method, the single beam of the simplified model shown in Figure 1 is regarded as a multisupport beam with simple support (unfixed in the longitudinal direction and fixed in the transverse direction) at each end. It is divided into a few portions according to the anchorage position area of each stay cable. Then, a single subsystem of three degrees of freedom has been comprised of three separated lumped mass blocks which are simplified from the beam portion, the stay cable, and the tower $[9,42]$. In line with this, there are $N$ self-excited subsystems and $2 N+1$ degree of freedom. After taking the left of the A-A cross section as an example, the simplified model of the $i^{\text {th }}$ subsystem is established, as shown in Figure 2.

In Figure 2, the tower is simplified as a lumped mass $m_{1}$ vibrating in the transverse direction with the air damping $c_{1}$ and bending stiffness $k_{1}$. The beam portion is simplified as a lumped mass $m_{2 i+1}$ vibrating vertically with air damping $c_{2 i+1}$ and bending stiffness $k_{2 i+1}$. The cable is simplified as a lumped mass $m_{2 i}$ vibrating in the transverse direction with air damping $c_{2 i}$. Two massless strings are connected at each end of the cable with instantaneous length $l_{i}$ and tensional rigidity $E A_{i}$. One end is connected to the tower with tension $T_{2 i-1}$; the angle between the tower and cable is $\theta_{2 i-1}$. Another is connected to the beam portion with tension $T_{2 i}$; the angle between the beam portion and the cable is $\theta_{2 i}$. Additionally, the displacements of the tower, cable, and beam portion related to the equilibrium position are $x_{1}, x_{2 i}$, and $x_{2 i+1}$, respectively.

Although this subsystem model is relatively rough that only considers the fundamental parameters such as length, mass, and tension, it is advantageous to reveal the characteristics of the parametric resonance of the subsystem. It is assumed that the initial state of the system is an equilibrium state. The geometric relationship of the subsystem satisfies the equations:

$$
\begin{aligned}
& l_{i}^{2}+\left(x_{2 i}-x_{2 i-1}\right)^{2}=\left(l_{i}+\Delta l_{2 i-1}\right)^{2}=l_{2 i-1}^{2}, \\
& \left(l_{i}+x_{2 i+1}\right)^{2}+x_{2 i}^{2}=\left(l_{i}+\Delta l_{2 i}\right)^{2}=l_{2 i}^{2}
\end{aligned}
$$




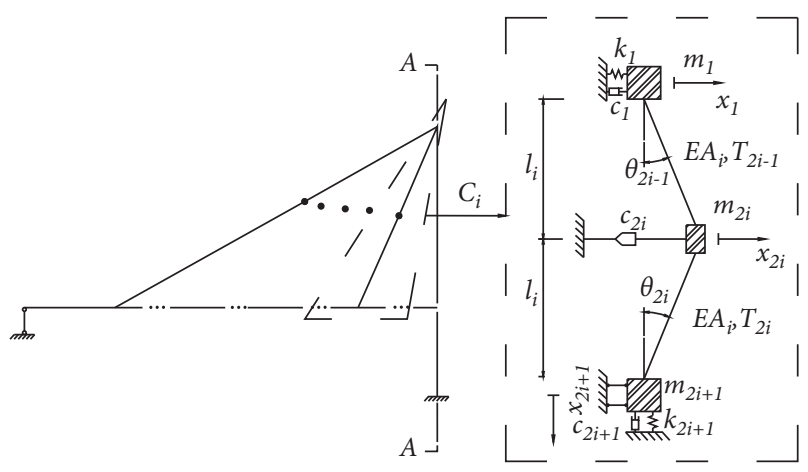

FIgURE 2: The $i^{\text {th }}$ simplified model in multidegrees of freedom.

$$
T_{i}=T_{0 i}+\Delta T_{i}=T_{0 i}+\frac{E A_{i} \cdot \Delta l_{i}}{l_{i}},
$$

where $T$ is the instantaneous tension and $\Delta T$ is the increment of the tension. Based on D'Alembert principle, with a few simple derivations, the vibration differential equations of the subsystem in the dimensionless form are derived as shown in the following equations:

where $l$ is the initial length of the massless string and $\Delta l$ is the increment of the length once resonance occurs. The conditional expression is

$$
\begin{aligned}
& \ddot{x}_{1}+\frac{c_{1}}{m_{1}} \dot{x}_{1}+\left(\frac{k_{1}}{m_{1}}+\frac{T_{0 i}}{m_{1} l_{i}}\right) x_{1}-\frac{T_{0 i}}{m_{1} l_{i}} x_{2 i}-\frac{3 E A_{i}}{2 \cdot m_{1} l_{i}^{3}} x_{1}^{2} x_{2 i}+\frac{E A_{i}}{2 \cdot m_{1} l_{i}^{3}} x_{1}^{3}+\frac{3 E A_{i}}{2 \cdot m_{1} l_{i}^{3}} x_{2 i}^{2} x_{1}-\frac{E A_{i}}{2 \cdot m_{1} l_{i}^{3}} x_{2 i}^{3}=0 \\
& \ddot{x}_{2 i}+\frac{c_{2 i}}{m_{2 i}} \dot{x}_{2 i}+\frac{2 \cdot T_{0 i}}{m_{2 i} l_{i}} x_{2 i}-\frac{T_{0 i}}{m_{2 i} l_{i}} x_{1}+\frac{3 \cdot E A_{i}}{2 \cdot m_{2 i} l_{i}^{3}} x_{1}^{2} x_{2 i}-\frac{E A_{i}}{2 \cdot m_{2 i} l_{i}^{3}} x_{1}^{3}+\frac{3 \cdot E A_{i}}{2 \cdot m_{2 i} x_{i}^{3}} x_{2 i}^{2} x_{1}+\frac{E A_{i}}{m_{2 i} l_{i}^{3}} x_{2 i}^{3}+\frac{E A_{i}}{2 \cdot m_{2 i} l_{i}^{3}} x_{2 i+1}^{2} x_{2 i}+\frac{E A_{i}}{m_{2 i} l_{i}^{2}} x_{2 i} x_{2 i+1}=0 \\
& \ddot{x}_{2 i+1}+\frac{c_{2 i+1}}{m_{2 i+1}} \dot{x}_{2 i+1}+\left(\frac{k_{2 i+1}}{m_{2 i+1}}+\frac{E A_{i}}{m_{2 i+1} l_{i}}\right) x_{2 i+1}+\frac{E A_{i}}{2 \cdot m_{2 i+1} l_{i}^{2}} x_{2 i+1}^{2}+\frac{E A_{i}}{2 \cdot m_{2 i+1} l_{i}^{2}} x_{2 i}^{2}=0
\end{aligned}
$$

Apparently, the bending stiffness of the beam cross section varies with the anchorage position of each cable. Thus, as for the beam with uniform distribution of the mass and load, the plastic performance is not consistently reflected at the mass point. If only considering the single beam constituted of the discrete lumped masses, the interaction between adjacent beam portions cannot be reflected effectively. Figure 3 takes the single beam constituted of two portions as an example.

In Figure 3, two strings $k_{11}$ and $k_{22}$, respectively, represent the bending stiffness of these two beam portions $M_{1}$ and $M_{2}$. Additionally, another string $k_{12}\left(=k_{21}\right)$ represents the interaction suffered from the resonance between $M_{1}$ and $M_{2}$. More specifically, it is the value of the force to be applied at $M_{1}$ to make $M_{2}$ produce a unit displacement along the direction of motion when the displacement of $M_{1}$ is kept at 0 . The specific value of the spring stiffness can be obtained by the flexibility matrix with the method of materials mechanics. Based on the multi-degree-of-freedom stiffness method, the vibration equations of this two-degree-of-freedom subsystem can be derived as shown in the following equations:

$$
\begin{aligned}
& M_{1} \ddot{x}_{1}+k_{11} x_{1}+k_{12} x_{2}=0, \\
& M_{2} \ddot{x}_{2}+k_{21} x_{1}+k_{22} x_{2}=0 .
\end{aligned}
$$

In line with this, ignoring the longitudinal displacement of beam portions once resonance occurs, a refined model of multicable resonance comprised of $N$ subsystems is shown in Figure 4.

The parameters in the system are listed in Table 1.

Following the geometry of the model, along with the similar simplified approach of the subsystem shown in Figure 2, the vibration equations of the refined model are normally derived based on the D'Alembert principle shown in the following equations:

$$
\begin{gathered}
m_{1} \ddot{x}_{1}=-k_{1} x_{1}-c_{1} \dot{x}_{1}+\sum_{i=1}^{N} T_{2 i-1} \sin \theta_{2 i-1}(i \in[1, N]), \\
{\left[m_{2 i}\right]\left\{\ddot{x}_{2 i}\right\}=-\left[c_{2 i}\right]\left\{\dot{x}_{2 i}\right\}-\left[T_{2 i-1}\right]\left\{\sin \theta_{2 i-1}\right\}-\left[T_{2 i}\right]\left\{\sin \theta_{2 i}\right\},}
\end{gathered}
$$




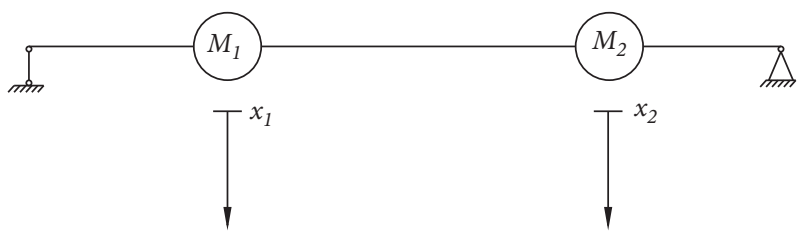

(a)

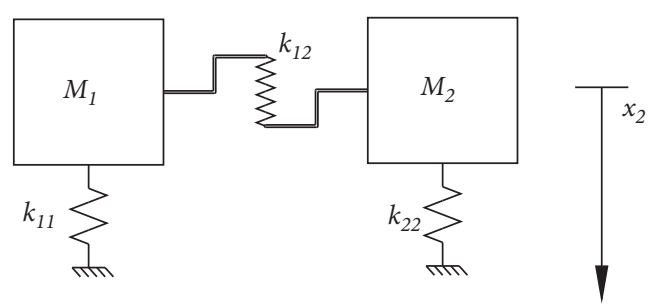

(b)

FIGURE 3: The simplified model of interaction between beam portions. (a) Two adjacent lumped mass blocks simplified from a single beam. (b) Interaction from two adjacent beam portions.

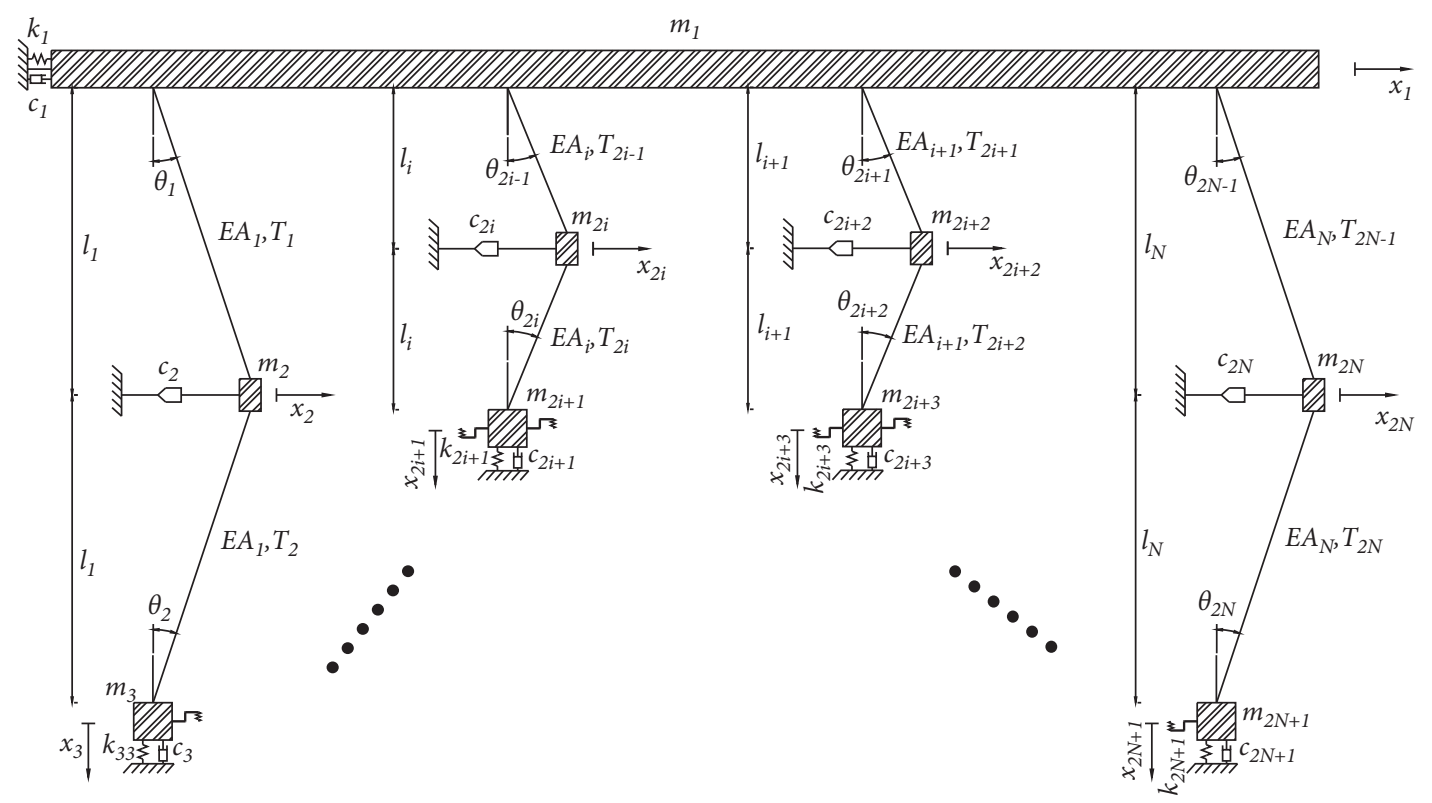

Figure 4: The simplified model for the parametric resonance of the multicable system in cable-stayed bridges.

TABle 1: Parameters of the refined model $(0 \leq i \leq N)$.

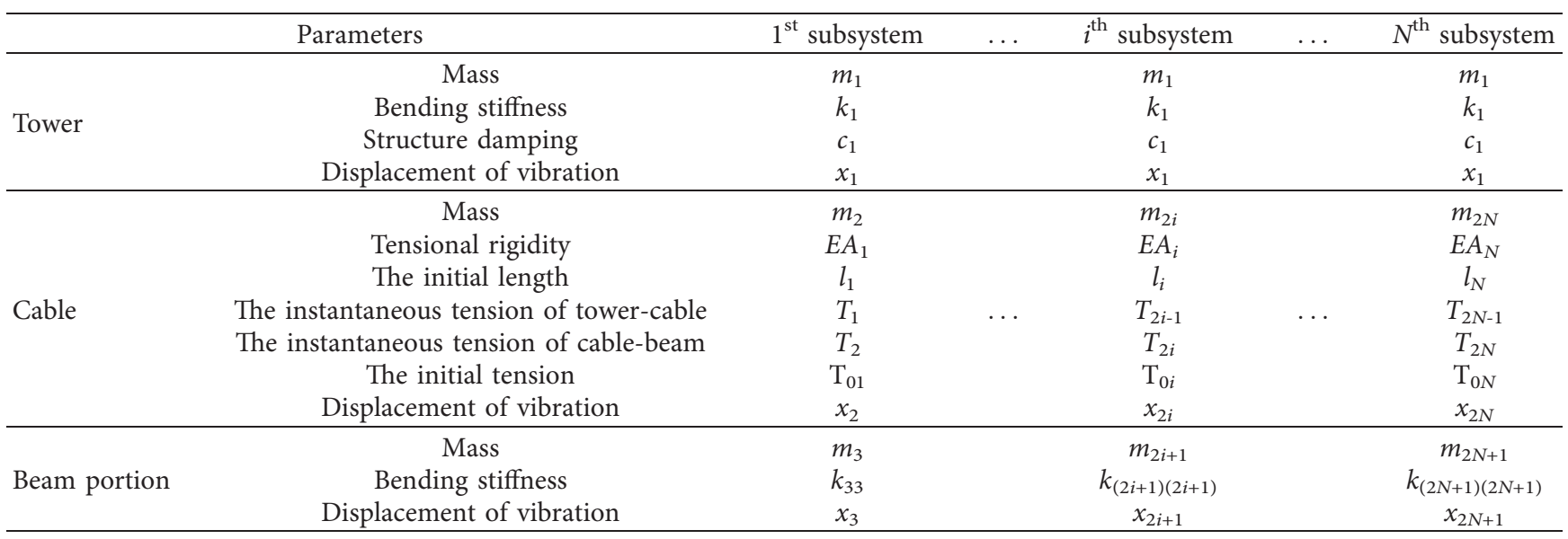

$$
\left[m_{2 i+1}\right]\left\{\ddot{x}_{2 i+1}\right\}=-\left[K_{(2 i+1)(2 i+1)}\right]\left\{x_{2 i+1}\right\}-\left[c_{2 i+1}\right]\left\{\dot{x}_{2 i+1}\right\}-\left[T_{2 i}\right]\left\{\cos \theta_{2 i}\right\}+\left[m_{2 i+1} g\right],
$$


where $\left\{\ddot{x}_{2 i}\right\}$ and $\left\{\dot{x}_{2 i}\right\}$ represent acceleration vector and velocity vector of the cable; $\left\{\ddot{x}_{2 i+1}\right\},\left\{\dot{x}_{2 i+1}\right\}$, and $\left\{x_{2 i+1}\right\}$ represent acceleration vector, velocity vector, and displacement vector of the beam portion; $\left\{\sin \theta_{2 i-1}\right\}$ represents the sine vector of the angle between the cable and the tower; $\left\{\sin \theta_{2 i}\right\}$ represents the sine vector of the angle between the cable and the beam portion during vibration; $\left\{\cos \theta_{2 i}\right\}$ represents the vector of the included angle between the cable and the beam section during vibration; $\left[m_{2 i}\right]$ and $\left[m_{2 i+1}\right]$ represent the mass matrix of the cable and beam portion; $\left[T_{2 i-1}\right]$ represents the cable force matrix of the cable connected to the tower during vibration; $\left[T_{2 i}\right]$ represents the cable force matrix of the cable connected to the beam portion during vibration; $\left[K_{(2 i+1)(2 i+1)}\right]$ represents the bending stiffness coefficient and respectively represent the of the beam portions; $g$ represents the acceleration due to gravity. Additionally, the mass matrix and the cable force matrix are diagonal matrices. The above symbols of calculation are shown in the following equations:

$$
\begin{aligned}
& \left\{\ddot{x}_{2 i}\right\}=\left\{\begin{array}{c}
\ddot{x}_{2} \\
\vdots \\
\ddot{x}_{2 N}
\end{array}\right\}, \\
& \left\{\dot{x}_{2 i}\right\}=\left\{\begin{array}{c}
\dot{x}_{2} \\
\vdots \\
\dot{x}_{2 N}
\end{array}\right\} \text {, } \\
& \left\{\ddot{x}_{2 i+1}\right\}=\left\{\begin{array}{c}
\ddot{x}_{3} \\
\vdots \\
\ddot{x}_{2 N+1}
\end{array}\right\} \text {, } \\
& \left\{\dot{x}_{2 i+1}\right\}=\left\{\begin{array}{c}
\dot{x}_{3} \\
\vdots \\
\dot{x}_{2 N+1}
\end{array}\right\} \text {, } \\
& \left\{x_{2 i+1}\right\}=\left\{\begin{array}{c}
x_{3} \\
\vdots \\
x_{2 N+1}
\end{array}\right\} \text {, } \\
& \left\{\sin \theta_{2 i-1}\right\}\left\{\begin{array}{c}
\sin \theta_{1} \\
\vdots \\
\sin \theta_{2 N-1}
\end{array}\right\} \text {, } \\
& \left\{\sin \theta_{2 i}\right\}=\left\{\begin{array}{c}
\sin \theta_{2} \\
\vdots \\
\sin \theta_{2 N}
\end{array}\right\}, \\
& \left\{\cos \theta_{2 i}\right\}=\left\{\begin{array}{c}
\cos \theta_{2} \\
\vdots \\
\cos \theta_{2 N}
\end{array}\right\} \text {, }
\end{aligned}
$$

$$
\begin{aligned}
& {\left[m_{2 i}\right]=\left[\begin{array}{lll}
m_{2} & & \\
& \ddots & \\
& & m_{2 N}
\end{array}\right],} \\
& {\left[m_{2 i+1}\right]=\left[\begin{array}{ccc}
m_{3} & & \\
& \ddots & \\
& & m_{2 N+1}
\end{array}\right] \text {, }} \\
& {\left[T_{2 i-1}\right]=\left[\begin{array}{lll}
T_{1} & & \\
& \ddots & \\
& & T_{2 N-1}
\end{array}\right],} \\
& {\left[T_{2 i}\right]=\left[\begin{array}{lll}
T_{2} & & \\
& \ddots & \\
& & T_{2 N}
\end{array}\right] \text {, }} \\
& {\left[K_{(2 i+1)(2 i+1)}\right]=\left[\begin{array}{ccc}
k_{33} & \cdots & k_{3(2 N+1)} \\
\vdots & \vdots & \vdots \\
k_{(2 N+1) 3} & \cdots & k_{(2 N+1)(2 N+1)}
\end{array}\right] \text {. }}
\end{aligned}
$$

According to the geometric characteristics of the simplified model and the single cable subsystem method, the vibration equations of the whole coupling system are obtained as shown in equations (7a)-(7c) after deducing and arranging:

$$
\begin{gathered}
\ddot{x}_{1}+\frac{c_{1}}{m_{1}} \dot{x}_{1}+\frac{k_{1}}{m_{1}} x_{1}+\sum_{i=1}^{N}\left(\frac{x_{2 i}-x_{1}}{l_{i}}\right)\left[T_{0 i}+\frac{E A_{i} \cdot\left(x_{2 i}-x_{1}\right)^{2}}{2 l_{i}^{2}}\right]=0, \\
i \in[1, N],
\end{gathered}
$$

$$
\begin{aligned}
{\left[M_{2 i}\right] } & \left\{\ddot{x}_{2 i}\right\}+\left[c_{2 i}\right]\left\{\dot{x}_{2 i}\right\}+\left[m_{2 i} \omega_{\mathrm{ci}}^{2}\right]\left\{x_{2 i}\right\}+\left[A_{1}^{i}\right] \cdot x_{1}+x_{1}{ }^{2}\left[A_{2}^{i}\right] \\
& \cdot\left\{x_{1}^{2} x_{2}+x_{2 i}^{2}\right\}+\left[A_{3}^{i}\right] \cdot x_{1}^{3}+\left[A_{4}^{i}\right]\left\{x_{2 i}^{3}\right\}+\left[A_{5}^{i}\right]\left\{x_{2 i+1}^{2} x_{2 i}\right\} \\
& +\left[A_{6}^{i}\right]\left\{x_{2 i} x_{2 i+1}\right\}=0,
\end{aligned}
$$

$$
\begin{aligned}
& {\left[M_{2 i+1}\right]\left\{\ddot{x}_{2 i+1}\right\}+\left[c_{2 i+1}\right]\left\{\dot{x}_{2 i+1}\right\}+\left[m_{2 i+1} \omega_{b i}^{2}\right]\left\{x_{2 i+1}\right\}+\left[B^{i}\right]} \\
& \cdot\left\{x_{2 i+1}^{2}+x_{2 i}^{2}\right\}+\left[\widetilde{K}_{i j}\right]\left\{x_{2 i+1}\right\}=0,
\end{aligned}
$$

where $\omega_{1}, \omega_{c i}$, and $\omega_{b i}$ represent the natural vibration frequency of the bridge tower, the cable, and the beam portion in the $i^{\text {th }}$ subsystem, respectively; the vectors including $\left\{x_{1}^{2} x_{2}+x_{2 i}^{2}\right\},\left\{x_{2 i+1}^{2} x_{2 i}\right\},\left\{x_{2 i} x_{2 i+1}\right\},\left\{x_{2 i+1}^{2}+x_{2 i}^{2}\right\}$ are column vectors and the form of the vectors are the same as $\left\{\dot{x}_{2 i}\right\}$ present in equation (6a); $\left[A_{1}^{i}\right] \sim\left[A_{7}^{i}\right]$ represent the coefficient matrix of the vibration differential equations of the cable; $\left[B^{i}\right]$ represents the coefficient matrix of the vibration differential equation of the beam; $\left[\widetilde{K}_{i j}\right]$ represents the effect coefficient matrix of the vibration beam portion on other beam portions in the multi-degree-of-freedom system, and it 
is also an $N \times N$ matrix. The above calculation symbols are shown in the following equations:

$$
\begin{aligned}
& \omega_{1}^{2}=\frac{k_{1}}{m_{1}}+\sum_{i=1}^{N} \frac{T_{0 i}}{m_{1} l_{i}}, \\
& {\left[\omega_{c i}^{2}\right]=\left[\begin{array}{ccc}
\frac{2 \cdot T_{01}}{m_{2} l_{1}} & \\
& \ddots & \\
& & \frac{2 \cdot T_{0 N}}{m_{2 N} l_{N}}
\end{array}\right]} \\
& {\left[\omega_{b i}^{2}\right]=\left[\begin{array}{ccc}
\frac{k_{33}}{m_{3}}+\frac{E A_{1}}{m_{3} l_{1}} & & \\
& \ddots & \\
& \frac{k_{(2 N+1)(2 N+1)}}{m_{(2 N+1)}}+\frac{E A_{N}}{m_{(2 N+1)} l_{N}}
\end{array}\right],} \\
& {\left[A_{1}^{i}\right]=\left[\begin{array}{ccc}
-\frac{T_{01}}{m_{2} l_{1}} & & \\
& \ddots & \\
& & -\frac{T_{0 N}}{m_{2 N} l_{N}}
\end{array}\right]} \\
& {\left[A_{2}^{i}\right]=\left[\begin{array}{ccc}
\frac{3 \cdot E A_{1}}{2 \cdot m_{2} l_{1}^{3}} & \\
& \ddots & \\
& & \frac{3 \cdot E A_{N}}{2 \cdot m_{2 N} l_{N}^{3}}
\end{array}\right]} \\
& {\left[A_{3}^{i}\right]=\left[\begin{array}{ccc}
-\frac{E A_{1}}{2 \cdot m_{2} l_{1}{ }^{3}} & \\
& \ddots & \\
& & -\frac{E A_{N}}{2 \cdot m_{2 N} l_{N}{ }^{3}}
\end{array}\right]} \\
& {\left[A_{4}^{i}\right]=\left[\begin{array}{ccc}
\frac{E A_{1}}{m_{2} l_{1}^{3}} & & \\
& \ddots & \\
& & \frac{E A_{N}}{m_{2 N} l_{N}^{3}}
\end{array}\right]} \\
& {\left[A_{5}^{i}\right]=\left[\begin{array}{ccc}
\frac{E A_{1}}{2 \cdot m_{2} l_{1}^{3}} & \\
& \ddots & \\
& & \frac{E A_{N}}{2 \cdot m_{2 N} l_{N}^{3}}
\end{array}\right],}
\end{aligned}
$$

$$
\begin{aligned}
& {\left[B^{i}\right]=\left[\begin{array}{ccc}
\frac{E A_{1}}{2 \cdot m_{3} l_{1}^{2}} & & \\
& \ddots & \\
& & \frac{E A_{N}}{2 \cdot m_{2 N+1} l_{N}^{2}}
\end{array}\right]} \\
& {\left[\widetilde{K}_{i j}\right]=\left[\begin{array}{ccccc}
0 & k_{35} & \cdots & k_{3(2 N-1)} & k_{3(2 N+1)} \\
k_{53} & 0 & k_{57} & \cdots & k_{5(2 N+1)} \\
\vdots & \vdots & \ddots & \vdots & \vdots \\
k_{(2 N-1) 3} & k_{(2 N-1) 5} & \cdots & 0 & k_{(2 N-1)(2 N+1)} \\
k_{(2 N+1) 3} & k_{(2 N+1) 5} & k_{(2 N+1) 7} & \cdots & 0
\end{array}\right] .}
\end{aligned}
$$

\section{The Mathematical Expression of the System}

3.1. Simplification of the Vibration Equations considering Stiffness Effect of the Beam. Generally, the length and the tension of the cable are changed periodically, promoting that the bending stiffness of the cross section of each beam portion is a nonlinear equation varied with time. It is too complex to solve or simulate the differential equations of the nonlinear resonance. To address this issue, the shear difference obtained from the finite difference is applied to simulate the interaction between adjacent beam portions. Figure 5 takes the beam portion of the $i^{\text {th }}(i \in[2, N-1])$ subsystem under an undamped condition as an example.

In Figure 5, the spring $k_{2 i+1}$ represents the effect of the bending stiffness for $i^{\text {th }}$ beam portion; $V_{2 i-1,2 i+1}$ and $V_{2 i+1,2 i+3}$ represent the shear force value on each side of this beam portion in this subsystem. The curvature of this beam portion can be approximately represented by the two-order central difference value of this beam portion:

$$
\frac{1}{\rho_{2 i+1}}=\left(\frac{\partial^{2} y}{\partial x^{2}}\right)_{2 i+1} \approx \frac{1}{\left(\Delta d_{2 i+1}\right)^{2}}\left(x_{2 i-1}-2 \cdot x_{2 i+1}+x_{2 i+3}\right) \text {. }
$$

The moment $\bar{M}_{2 i+1}$ and shear force value have been represented in the following equations:

$$
\begin{aligned}
\bar{M}_{2 i+1} & =-E I \cdot \frac{1}{\rho_{2 i+1}}=-E I \cdot\left(\frac{\partial^{2} y}{\partial x^{2}}\right)_{2 i+1} \\
& \approx-E I \cdot \frac{1}{\left(\Delta d_{2 i+1}\right)^{2}}\left(x_{2 i-1}-2 \cdot x_{2 i+1}+x_{2 i+3}\right), \\
V_{2 i-1,2 i+1} & =\frac{\bar{M}_{2 i+1}-\bar{M}_{2 i-1}}{\Delta d_{2 i+1}},
\end{aligned}
$$



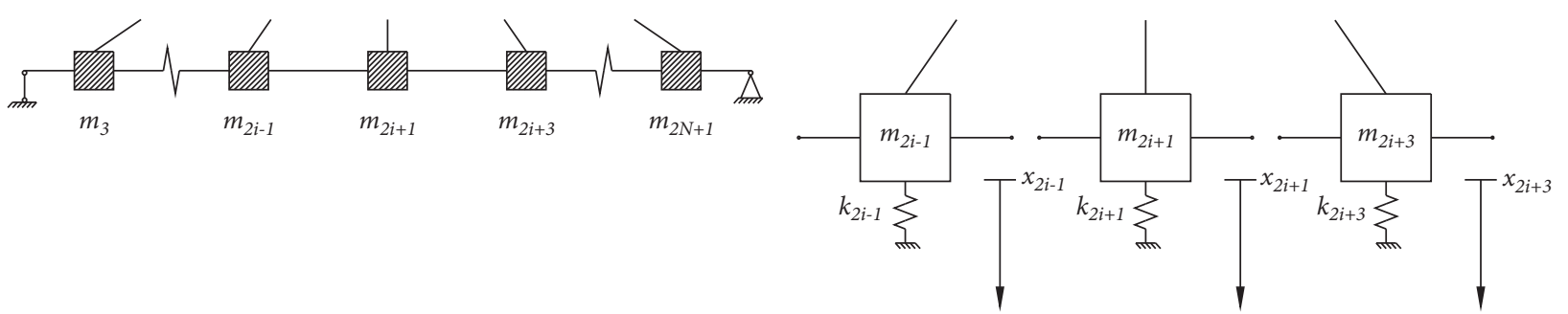

(a)

(b)

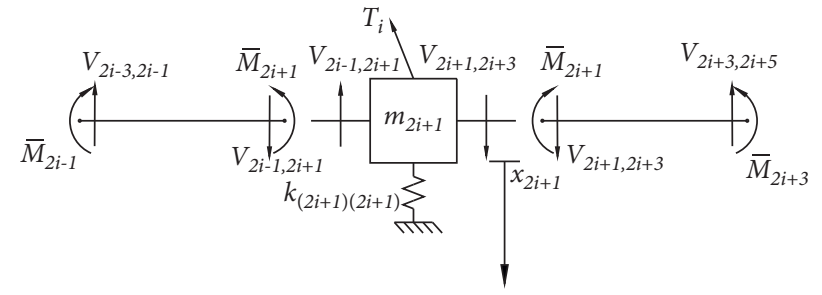

(c)

FIgURE 5: The beam portion model of $i^{\text {th }}$ subsystem and its adjacent beam portions. (a) Different simplified beam portions in a single beam. (b) The $i^{\text {th }}$ simplified subsystem and its adjacent beam portions. (c) The mechanical system of the beam portion in $i^{\text {th }}$ subsystem.

$$
V_{2 i+1,2 i+3}=\frac{\bar{M}_{2 i+3}-\bar{M}_{2 i+1}}{\Delta d_{2 i+3}}
$$

where $E I$ represents the flexural rigidity; $d_{2 i+1}$ represents the distance from $(i-1)^{\text {th }}$ to $i^{\text {th }}$ cable anchorage position; and $V_{2 i+1}$ represents the shear difference between the left and right sides of the beam portion of the $i^{\text {th }}$ subsystem. Assuming that the length of each beam portion is obtained the same $\left(\Delta d_{2 i+1}=\Delta d_{2 i+3}=\Delta d\right)$, the interaction between adjacent beam portions in a multicable system is appropriately represented by the shear difference (see Figure 6).

In Figure 6, it is essential to notice that the shear is applied to represent the effect of the interaction between adjacent beam portions, and the relationship satisfies the equation shown in the following equation:

$$
\begin{aligned}
& {\left[k_{(2 i+1) 3} \cdots k_{(2 i+1)(2 N+1)}\right]\left[\begin{array}{c}
x_{3} \\
\vdots \\
x_{2 N+1}
\end{array}\right] \approx \Delta V_{2 i+1}=V_{2 i+1,2 i+3}} \\
& \quad-V_{2 i+1,2 i-1} .
\end{aligned}
$$

Substitute equation (9) into equations (10a)-(10c) to obtain

$$
\Delta V_{2 i+1}=\frac{-E I}{(\Delta d)^{3}}\left(x_{2 i-3}-4 \cdot x_{2 i-1}+6 \cdot x_{2 i+1}-4 \cdot x_{2 i+3}+x_{2 i+5}\right) .
$$

In Figure 1, the beam portion of the $C_{1}$ subsystem is near the simply supported end on the left, while the beam portion of the $C N$ subsystem is near the simply supported end on the right, promoting that their displacement and bending moment are both zero:

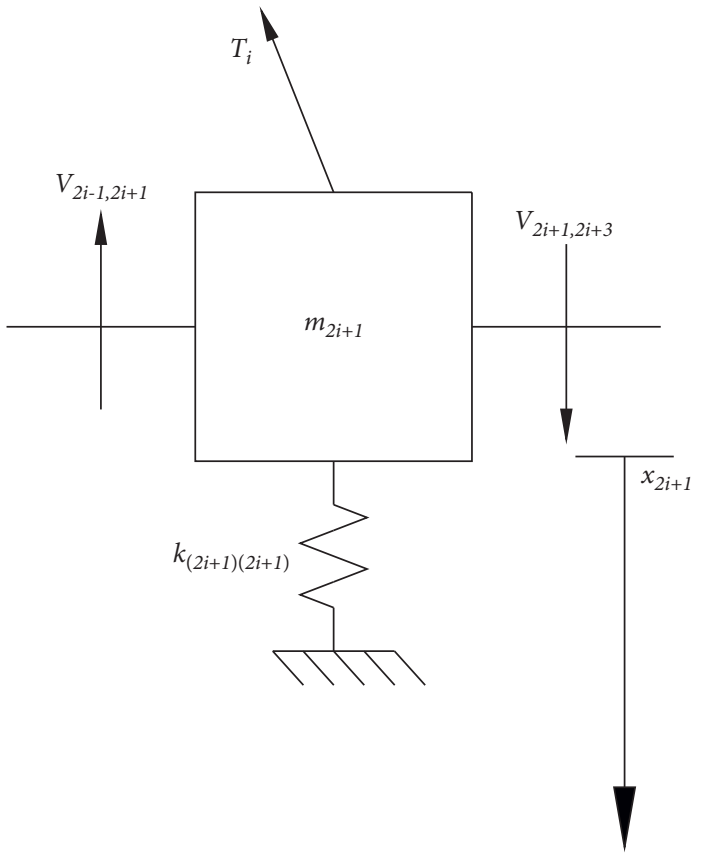

FIGURE 6: The equivalent balance between the shear force with the stiffness spring.

$$
\begin{aligned}
& \frac{1}{\rho_{3-}}=\left(\frac{\partial^{2} y}{\partial x^{2}}\right)_{3} \approx \frac{1}{(\Delta d)^{2}}\left(-2 x_{3}+x_{5}\right), \\
& \frac{1}{\rho_{(2 N+1)+}}=\left(\frac{\partial^{2} y}{\partial x^{2}}\right)_{(2 N+1)} \approx \frac{1}{(\Delta d)^{2}}\left(-2 x_{2 N+1}+x_{2 N-1}\right),
\end{aligned}
$$

where $\rho_{3-}$ and $\rho_{(2 N+1)+}$ represent the curvature of the beam left of the $C_{1}$ subsystem and right of the $C_{N}$ subsystem, respectively. Moreover, the bending moment and shear difference between these two subsystems are calculated as follows: 


$$
\begin{aligned}
\bar{M}_{3} & \approx-E I \cdot \frac{1}{(\Delta d)^{2}}\left(-2 \cdot x_{3}+x_{5}\right), \\
\bar{M}_{2 N+1} & \approx-E I \cdot \frac{1}{(\Delta d)^{2}}\left(-2 \cdot x_{2 N+1}+x_{2 N-1}\right), \\
\Delta V_{3} & =\frac{\bar{M}_{5}-\bar{M}_{3}}{\Delta d}-\frac{\bar{M}_{3}-0}{\Delta d} \\
& =\frac{-2 \cdot \bar{M}_{3}+\bar{M}_{5}}{\Delta d} \\
& =\frac{-E I}{(\Delta d)^{3}} \cdot\left(5 \cdot x_{3}-4 \cdot x_{5}+x_{7}\right), \\
\Delta V_{2 N+1} & =\frac{0-\bar{M}_{(2 N+1)}}{0.5 \Delta d}-\frac{\bar{M}_{(2 N+1)}-\bar{M}_{(2 N-1)}}{\Delta d} \\
& =\frac{-E I}{(\Delta d)^{3}} \cdot\left(5 \cdot x_{2 N+1}-4 \cdot x_{2 N-1}+x_{2 N-3}\right) .
\end{aligned}
$$

3.2. The Vibration Equations of the Multicable System. Substituting equations (14a), (14b), (15a) and (15b) into equations $(7 a)-(7 c)$, the vibrations equations of the parametric resonance model shown in Figure 4 are obtained as shown in equations (16a)-(16c):

$$
\ddot{x}_{1}+\frac{c_{1}}{m_{1}} \dot{x}_{1}+\frac{k_{1}}{m_{1}} x_{1}+\sum_{i=1}^{N}\left(\frac{x_{2 i}-x_{1}}{l_{i}}\right)\left[T_{0 i}+\frac{E A_{i}\left(x_{2 i}-x_{1}\right)^{2}}{2 \cdot l_{i}^{2}}\right]=0 \text {, }
$$

$$
\begin{gathered}
{\left[m_{2 i}\right]\left\{\ddot{x}_{2 i}\right\}+\left[c_{2 i}\right]\left\{\dot{x}_{2 i}\right\}+\left[m_{2 i} \omega_{c i}^{2}\right]\left\{x_{2 i}\right\}+\left[A_{1}^{i} x_{1}\right]} \\
+\left[A_{2}^{i} x_{1}^{2}\right]\left\{x_{1}^{2} x_{2}+x_{2 i}^{2}\right\}+\left[A_{3}^{i} x_{1}^{3}\right]+\left[A_{4}^{i}\right]\left\{x_{2 i}^{3}\right\} \\
+\left[A_{5}^{i}\right]\left\{x_{2 i+1}^{2} x_{2 i}\right\}+\left[A_{6}^{i}\right]\left\{x_{2 i} x_{2 i+1}\right\}=0, \\
{\left[m_{2 i+1}\right]\left\{\ddot{x}_{2 i+1}\right\}+\left[c_{2 i+1}\right]\left\{\dot{x}_{2 i+1}\right\}+\left[m_{2 i+1} \widehat{\omega}_{b i}^{2}\right]\left\{x_{2 i+1}\right\}} \\
+\left[B^{i}\right]\left\{x_{2 i+1}^{2}+x_{2 i}^{2}\right\}+\frac{-E I}{(\Delta d)^{3}}\left[D_{N \times N}\right]\left\{x_{2 i+1}\right\}=0,
\end{gathered}
$$

where $\left[\widehat{\omega}_{b i}^{2}\right]$ represents the natural vibration frequency matrix of the beam portion of the $i^{\text {th }}$ subsystem simplified by the difference method and $\left[D_{N \times N}\right]$ represents the coefficient matrix of the difference method and is also an $N$ order matrix. The equations of these two calculation symbols are as follows:

$$
\begin{aligned}
& {\left[\widehat{\omega}_{b i}^{2}\right]=\left[\begin{array}{ccc}
\frac{E A_{1}}{m_{3} l_{1}}-5 \frac{E I}{m_{3}(\Delta d)^{3}} & & \\
& \frac{E A_{2}}{m_{5} l_{2}}-6 \frac{E I}{m_{5}(\Delta d)^{3}} & \\
& \ddots & \\
& \frac{E A_{(N-1)}}{m_{(2 N-1)} l_{(N-1)}}-6 \frac{E I}{m_{(2 N-1)}(\Delta d)^{3}} & \\
& & \frac{E A_{N}}{m_{(2 N+1)} l_{N}}-5 \frac{E I}{m_{(2 N+1)}(\Delta d)^{3}}
\end{array}\right],} \\
& {\left[D_{N \times N}\right]=\left[\begin{array}{cccccccccc}
0 & 4 & -1 & & & & & & \\
4 & 0 & 4 & -1 & & & & & \\
-1 & 4 & 0 & 4 & -1 & & & & \\
& -1 & 4 & 0 & 4 & -1 & & & \\
& & \ddots & \ddots & \ddots & \ddots & \ddots & & \\
& & & -1 & 4 & 0 & 4 & -1 & \\
& & & & -1 & 4 & 0 & 4 & -1 \\
& & & & & -1 & 4 & 0 & 4 \\
& & & & & & -1 & 4 & 0
\end{array}\right]}
\end{aligned}
$$

3.3. Verification by Degenerating into a Single Cable System. Reference [42] presented the research of one single cable system with the same simplification method. To verify the expressions, the multicables system degenerates to one single cable system. More specifically, $\Delta \mathrm{d}$ from equations (16a), (16b) and (16c) is set large enough to ensure the value of $E I /(\Delta d)^{3}$ close to zero, making the beam portion independent. The detailed parameters are adopted from [42]. Moreover, a simplified model of one single cable system is established with the finite element method through ABAQUS/Explicit. The displacements of the cable vibration with the present method (simulation analytical solution, SAS), the finite element method (finite element solution, FES), and [42] (reference analytical results, RAR) are presented in Figure 7. Otherwise, the results obtained from the present 


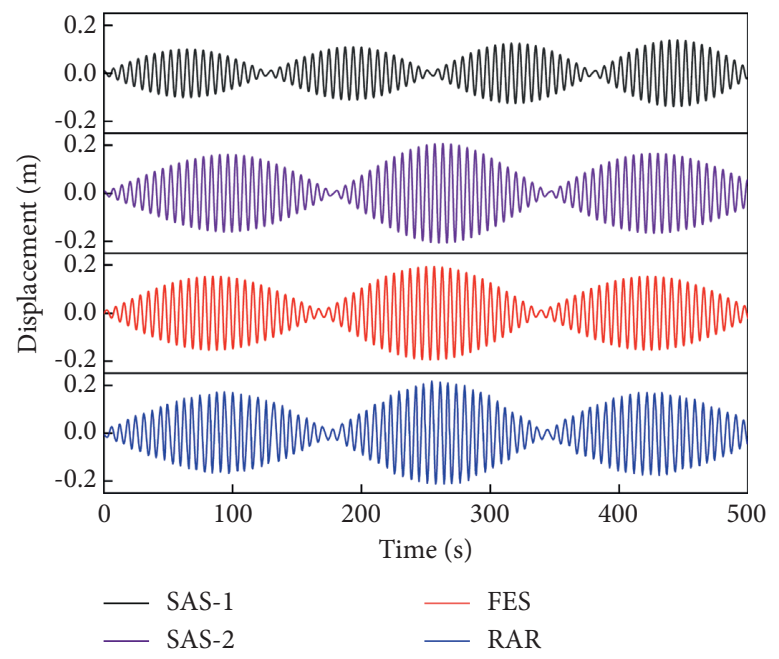

(a)
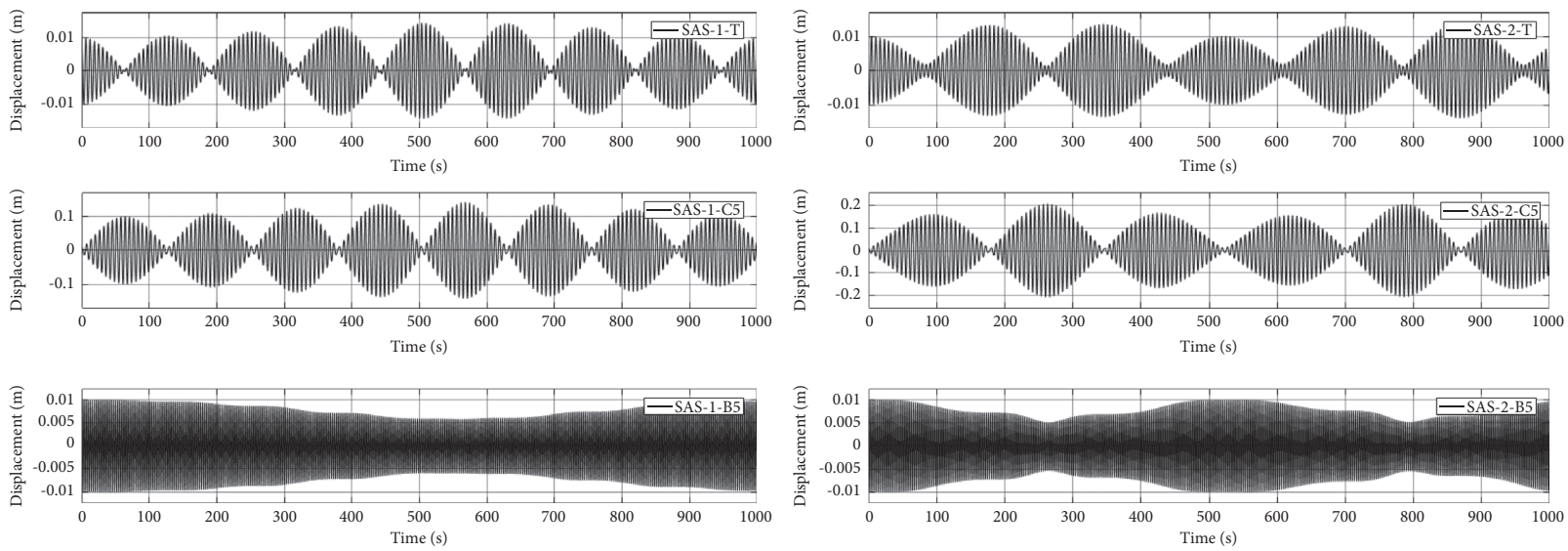

(b)

Figure 7: The comparison of calculation results under different conditions. (a) The comparison of different analytical solutions. (b) The comparison of calculation results under different conditions of SAS.

method are comprised of two conditions. One of them, symbolled as SAS-1 in Figure 7, considers the effect from other subsystems and analyzes under the multicable condition by making $N \in[1,10]$ in equation (16a). It should be noticed that the cable parameters of other subsystems do not meet the parametric resonance condition. Another one, which is symbolled as SAS-2 in Figure 7, is ignoring the influence of the multicable system on the vibration motion of the tower by making $N=i=5$ in equation (16a).

From Figure $7(a)$, the resonance phenomena of the cable are significantly observed. Particularly, in Figure 7(b), the variation trend is a little bit different from SAS-1 to SAS-2. When SAS-1 occurs, the cable amplitude still gradually increases while the increasing period is delayed. It indicates that the total energy of the system is transformed between the pylon and all cables when the condition of SAS-1 is considered, resulting in the extension of the vibration period of the whole bridge. Under this condition, after taking the interaction between beam portions into account, the resonance of the subsystem is disturbed to a different extent, and the maximum amplitude is also lower than that of other working conditions. In addition, the characteristics of vibration displacement through SAS-2, FES, and RAR stay the same. It indicates that the model in this paper can simulate the essential character of parametric resonance well.

\section{Extension of the Analysis to the Multicable Coupling System}

4.1. Parameters of the Case Study. To further investigate the interactions of the multicable coupling system, a simplified model of the multicable system (see Figure 8 ) is proposed to carry on a theoretical numerical simulation analysis. The parameters are consulted in $[9,42]$.

In Figure 8, there are 10 cables anchored to the single beam comprised of 10 beam portions, corresponding to the $C_{1}-C_{10}$ subsystem, respectively. The investigation aims to propose a refined model for the mechanism analysis of the parametric resonance. Thus, it is assumed that the distance 


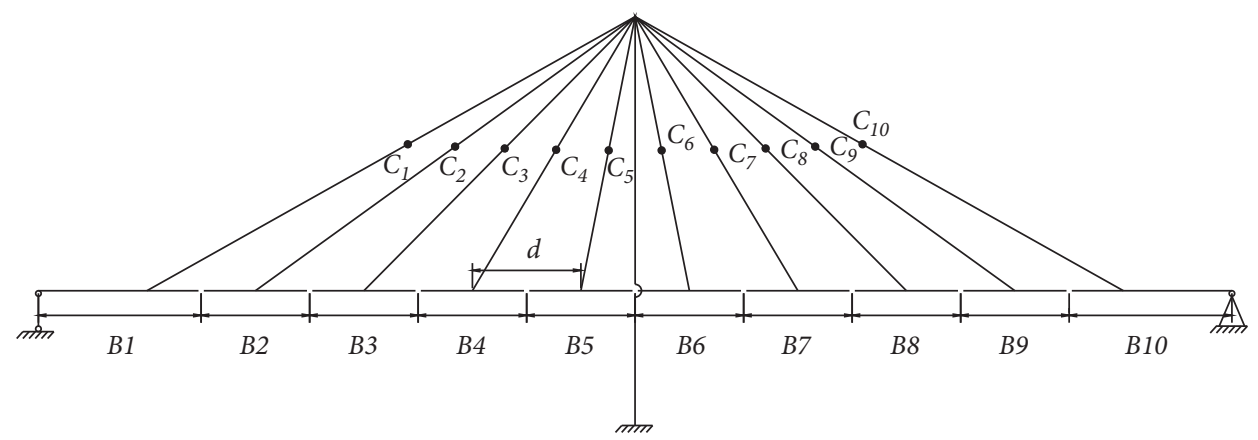

FIGURE 8: The simplified model of parametric resonance for the multicable system.

TABLE 2: The basic parameters of the components in the $C i$ subsystem.

\begin{tabular}{|c|c|c|}
\hline & The parameter of the component (symbol) & The values \\
\hline & Tower $\left(m_{1}\right)$ & $2000 \mathrm{~kg}$ \\
\hline Mass & $\begin{array}{c}\text { The same for all beam portions }\left(m_{2 i+1}\right) m_{3}=m_{5}=m_{7}=m_{9} m_{3}=m_{5}=m_{7}=m_{9} m_{3}=m_{5}=m_{7}=m_{9} \\
\text { The same for all the unit mass of the cable }\left(_{\mu} m_{2 i}\right)\end{array}$ & $\begin{array}{l}1000 \mathrm{~kg} \\
1 \mathrm{~kg} / \mathrm{m}\end{array}$ \\
\hline Stiffness & $\begin{array}{c}\text { The bending stiffness of the tower }\left(k_{1}\right) \\
\text { The bending stiffness of the beam portion }(E I) \\
\text { The tensional rigidity of the cable }\left(E A_{i}\right)\end{array}$ & $\begin{array}{l}10^{4} \mathrm{kN} / \mathrm{m} \\
5 * 10^{4} \mathrm{kN} \cdot \mathrm{m}^{2} \\
5 * 10^{4} \mathrm{kN}\end{array}$ \\
\hline Distance & The distance between the cable acting points on the beam $(\Delta \mathrm{d})$ & $10 \mathrm{~m}$ \\
\hline Air damping & All of the component & 0 \\
\hline
\end{tabular}

$d$ between the anchorage position of each stay cable, the mass $m_{2 i+1}$ of each portion, and the elastic modulus $E I$ are all the same. The basic parameters are shown in Table 2.

Based on the geometric relationship of the simplified model, the cable parameters are shown in Table 3.

From the parameters shown in Table 3, there are no occurrences of parametric resonance in the system. Subsequently, the $C_{5}$ subsystem is selected as a comparative subsystem.

\subsection{The Vibration Analysis of the Single Beam Comprised of} Discrete Beam Portions. In previous studies, the cable is anchored on the single beam, supporting that the natural frequency of the beam portion is the natural frequency of the single beam. The cables suffer from more or less relevant resonance under the excitation from the beam portion vibration response in the same subsystem. Specifically, if the parametric resonance conditions are satisfied in this subsystem, severe oscillations will occur on the subsystem. This paper proposes a refined model comprised of several discrete subsystems, promoting that the single beam is comprised of several beam portions. Thus, the effect of the excitation from the beam portion is composed of two parts: one is the effect provided by the bending stiffness of the beam portion and another is the restoring force provided by the cable. Additionally, the cable anchors at the portion of the beam, leading to these two components (the cable and the beam portion) have the common boundary and displacement when resonance occurs. With the response excitation from the beam portion, the length and the tension of the cable are changed periodically, promoting that the influence for the cable also changes periodicity. Figure 9 demonstrates the relationship between these two factors.
TABLE 3: The parameters of each subsystem cable.

\begin{tabular}{lcc}
\hline Abbreviation & Length $(\mathrm{m})$ & Tension $(\mathrm{kN})$ \\
\hline$C_{1}$ & 50 & 1200 \\
$C_{2}$ & 40 & 900 \\
$C_{3}$ & 32 & 500 \\
$C_{4}$ & 25 & 350 \\
$C_{5}$ & 20 & 200 \\
$C_{6}$ & 20 & 200 \\
$C_{7}$ & 25 & 350 \\
$C_{8}$ & 32 & 500 \\
$C_{9}$ & 40 & 900 \\
$C_{10}$ & 50 & 1200 \\
\hline
\end{tabular}

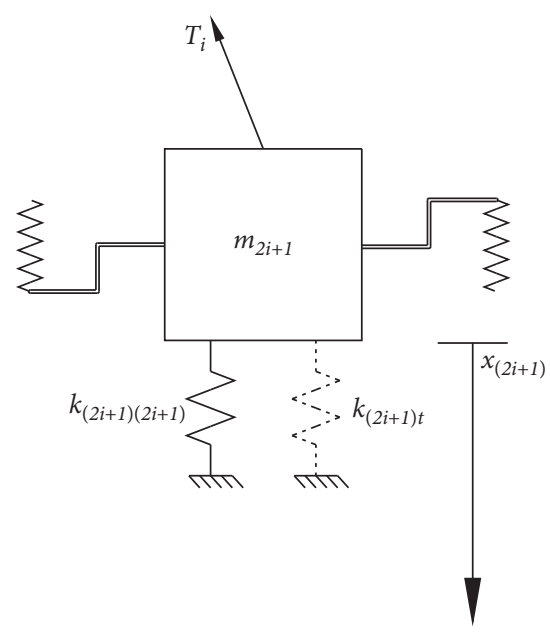

FIGURE 9: Excitation action decomposition of beam portion in one single subsystem. 
In Figure 9, two springs are adopted to represent these two factors: one symbolled as $k_{(2 i+1) t}$ represents the effect from the cable and another symbolled as $k_{(2 i+1)(2 i+1)}$ represents the effect from the beam portion. In addition, it is noticeable that there also exist the indirect influences of cable tension from adjacent cables, $k_{(2 i+1)(2 j+1) t}$, while they are not exhibited in Figure 9 . The parallel effect of these springs is accurately the excitation applied to the cable. Apparently, if the ratio of the natural frequency of this parallel effect to the natural frequency of the cable satisfies the parametric resonance conditions, the cable exhibits severe oscillations. In line with this, the equations of the beam portion vibration frequency shown in equations (8c) and (17a) take on another meaning.

The vibration equation is obtained based on the multidegree-of-freedom stiffness method as follows:

$$
\omega_{b i}^{2}=\frac{E A_{i}}{m_{(2 i+1)} l_{i}}+\frac{k_{(2 i+1)(2 i+1)}}{m_{(2 i+1)}}
$$

where $k_{(2 i+1) \mathrm{t}}=E A_{i} / l_{i}$. The vibration equation is obtained according to the finite difference method as follows:

$$
\widehat{\omega}_{b i}^{2}=\frac{E A_{i}}{m_{(2 i+1)} l_{i}}+\left[-\alpha \cdot \frac{E I}{m_{2 i+1} \cdot(\Delta d)^{3}}\right], \quad \alpha=\left\{\begin{array}{l}
5, i=1 \text { or } i=N, \\
6,1<i<N,
\end{array}\right.
$$

where $\widehat{\omega}_{b i}$ represents the resonance frequency of the excitation from the beam portion. Following this idea, the single beam in Figure 9 can be transformed into an integrated system comprised of several discrete beam portions that connected strings, as shown in Figure 10.

In Figure 10 (1), the single beam anchored with 10 cables is simplified to an integrated system comprised of several discrete beam portions with shears by the present method of this paper as shown in Figure 10 (4). It is noticeable that the reduction objects of the shear difference include the bending stiffness of the single beam at $\mathrm{Ci}$ \# cable anchored position section, $k_{(2 i+1)(2 i+1)}$, the indirect influence of the bending stiffness from adjacent beam portions, $k_{(2 i+1)(2 j+1)}(i \neq j)$ and the indirect influence of the cable tension from adjacent cables, $k_{(2 i+1)}(2 j+1) t(i \neq j)$. To accurately analyze the vibration mode of the single beam, the FES and SAS are adopted to simulate, respectively. The vibration frequency and the vertical mode shapes of the integrated system are presented in Table 4 and Figure 11, respectively.

In Table 4, the frequency of the system with different calculation methods is almost the same. There is little difference between the first two modes or the third and fourth modes. It illustrates that the fundamental vibration shapes and frequencies of the components occupying these two groups of lower-order modes are not much different. Particularly in Figure 11, the vertical mode shapes obtained by two methods variated with almost the same trend. It is evident from the mode analysis of the integrated system that the numerical simulation method based on the shear difference proposed in this paper can accurately simulate the effect on the vibration caused by the bending stiffness of the single beam.

4.3. The Effect of Adjacent Beam Portions on the Resonance. For more accurate investigation on the effect of adjacent beam portions on the resonance, in the following research, the bending stiffness of the beam portion or tower in the $C_{5}$ subsystem is modified to satisfy the working conditions from $S_{1}$ to $S_{4}$. The condition instructions are shown in Table 5.

Based on SIMULINK/MATLAB, the resonance response of each component under the working condition from $S_{1}$ to $S_{4}$ is obtained by using the algorithm of Runge-Kutta with an average step of $0.02 \mathrm{~s}$, as shown in Figure 12.

In Figure 12, the variable resonance behavior in the multicable system is easily observed when the coupling resonance of the tower-cable occurred. Obviously, the main reason is that the parameters of the cables in adjacent subsystems have little change, which leads to the natural frequency ratio of the cable-tower being also relatively similar in several subsystems. There exists mutual interference between different resonant subsystems. However, the coupling characteristic of the $C_{5}$ subsystem shown in Figure 12 is approximately the same as that of parametric resonance without considering the interaction of the beam portions. The resonance response of each component in adjacent subsystems is selected in Figure 13.

In Figures 13(a) and 13(c), when the cable-beam parametric resonance is occurring, the resonance response of the beam portion in two adjacent subsystems has been influenced. In contrast, the resonance response of the cable in adjacent subsystems has little change. It indicates that the vibration response of the cable in the adjacent beam portions may increase due to the excitation of resonance beam portions. However, if the condition of coupling resonance is not satisfied in the subsystem, the cable in two adjacent subsystems cannot be excited to exhibit severe oscillations. In short, when the subsystem satisfies the resonance conditions, the global resonance will cause severe local resonance.

For further investigation, the parameters of the subsystems which are symmetric with the tower are selected the same. The maximum resonance response values of different beam portions under various working conditions are shown in Table 6.

To minimize the influence on the parametric resonance of the cable caused by the symmetry of cable-stayed bridge properties, selecting that the subsystems of $S_{1}-S_{4}$ and $S_{2}-S_{3}$ are two comparison conditions, the amplitude difference of the corresponding beam portion between the two working conditions is shown in Figure 14.

In Figure 14, there are five pairs of comparison conditions in the global bridge system. When the resonance occurs, most of the energy of the system will be transferred to the cable, which excites the cable to vibrate violently. At this time, the maximum amplitude of the beam portion in the resonance subsystem decreases sharply. Moreover, it indicates that the beam portions where coupling resonance occurs have a certain effect on the resonance response of the beam portions in adjacent subsystems. Generally speaking, this effect is more obvious within the two adjacent subsystems. To study the effect of the matching between the natural frequencies of each degree of freedom on the vibration characteristics of the parametric resonance system and adjust the initial tension of the cable, the curve of the maximum vibration amplitude of $C_{5}$ varies with the frequency ratio as presented in Figure 15. 

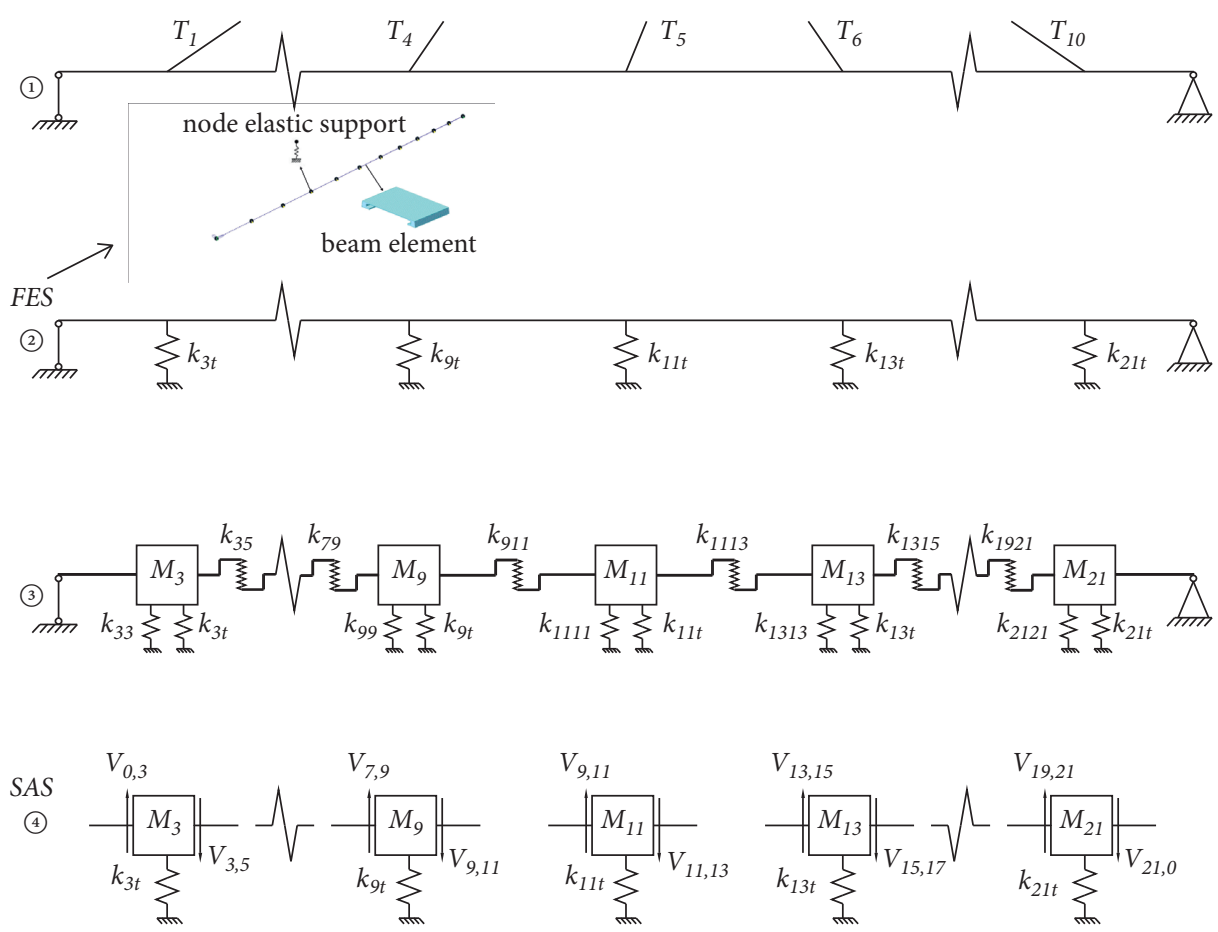

FIgURE 10: The simplified model of the single beam.

TABLE 4: The model properties of the integrated system.

\begin{tabular}{lcccc}
\hline Mode number & Abbreviation & $f(\mathrm{~Hz})$ & & SAS \\
\hline 1 & & FEA & 0.854 & 0.2 \\
2 & $V_{1}$ & 0.852 & 0.855 & 0.3 \\
3 & $V_{2}$ & 0.853 & 1.006 & 0.2 \\
4 & $V_{3}$ & 1.004 & 1.007 & 0.2 \\
5 & $V_{4}$ & 1.005 & 1.148 & 0.4 \\
\hline
\end{tabular}

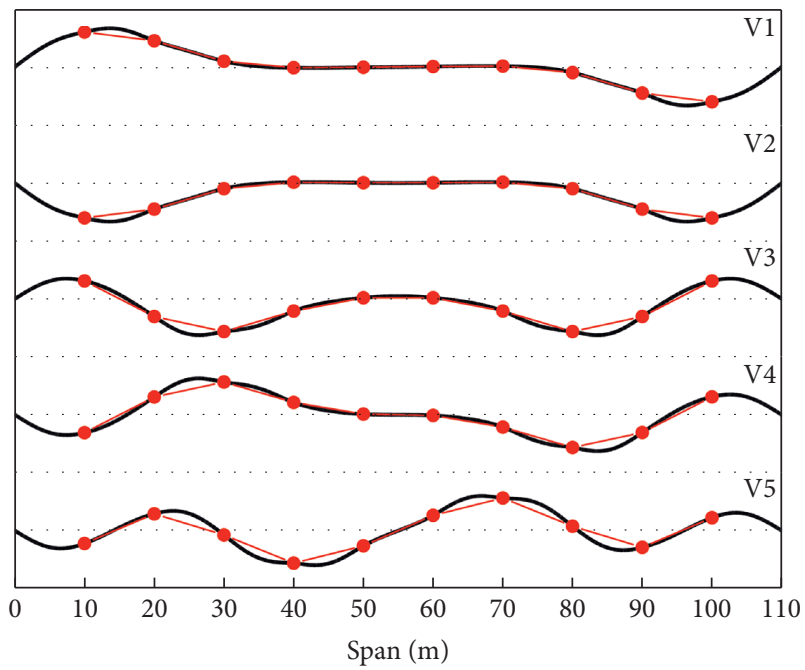

- FES mode shape

$\rightarrow$ SAS mode shape

FIGURE 11: Vertical mode shapes.
TABLE 5: Instruction of each working condition setting.

\begin{tabular}{lc}
\hline Abbreviation & Instruction of small operating conditions \\
\hline$S_{1}$ & Coupling resonance occurs only in tower-cable \\
$S_{2}$ & Coupling resonance occurs only in cable-beam \\
$S_{3}$ & Coupling resonance occurs in tower-cable-beam \\
$S_{4}$ & The system has no coupling resonance \\
\hline
\end{tabular}

As seen in Figure 15, after taking the stiffness of the tower or the beam portion into accounting, the sensitivity of the cable-beam resonance becomes lower. The resonance interval has changed abruptly around 0.5. Therefore, the cable-beam resonance probability caused by material properties will be further reduced in practical engineering. In addition, the frequency ratio curve of the tow-cable shows a slow downward trend, and its resonance period is between 1.0 and 1.1. If the vibration frequency between adjacent cables does not change much in practical engineering, the coupling resonance between tower and multistay cables will be generated due to high probability. Therefore, to avoid the occurrence of tow-cable parameter resonance, it is not 

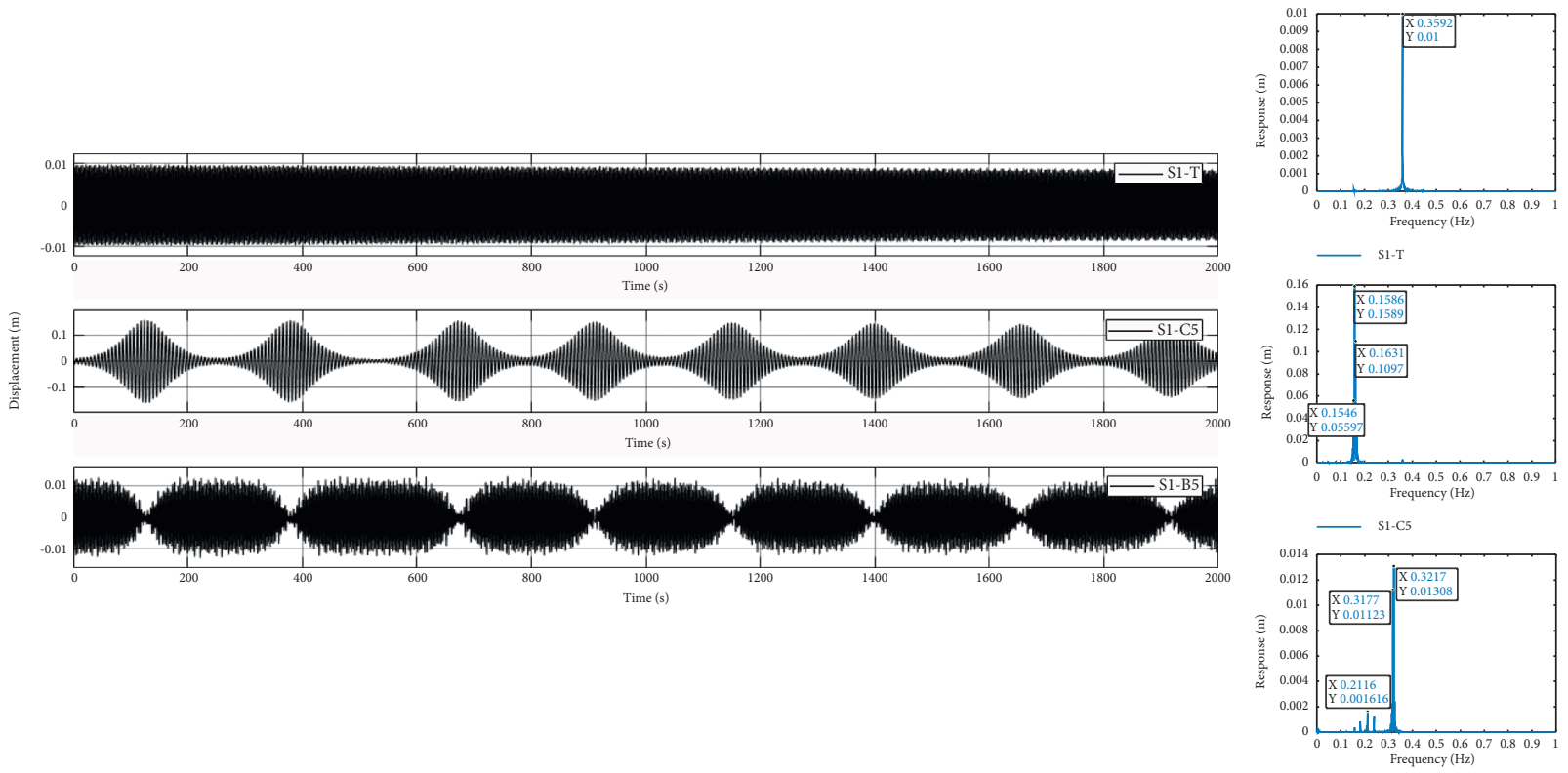

(a)
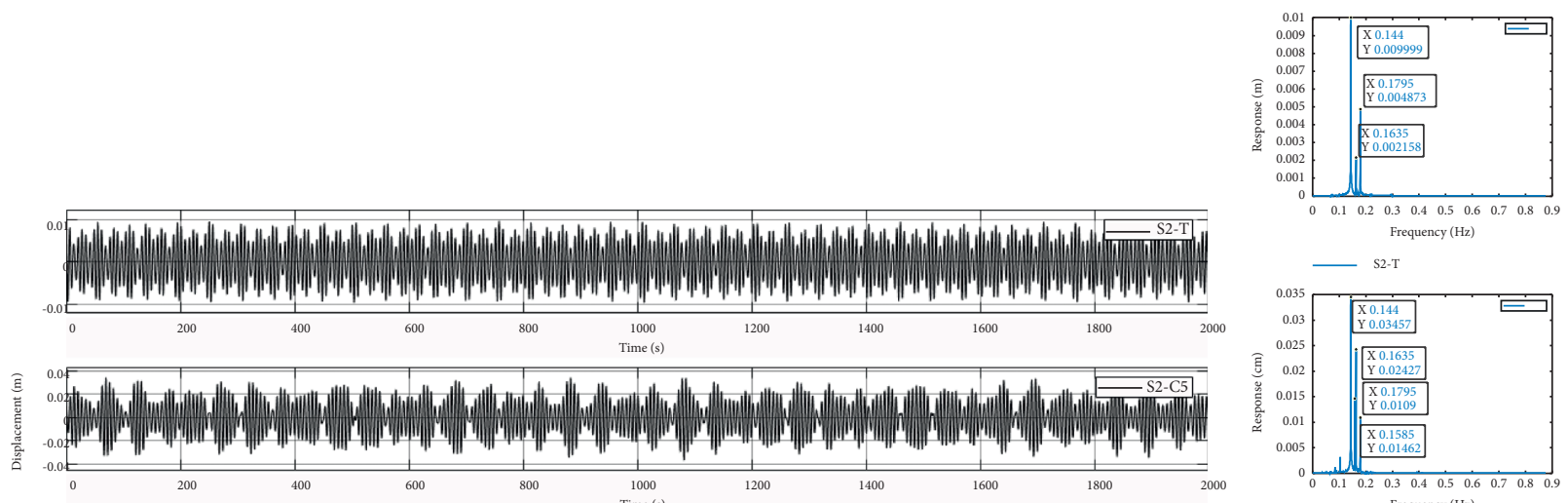
Frequency $(\mathrm{Hz})$
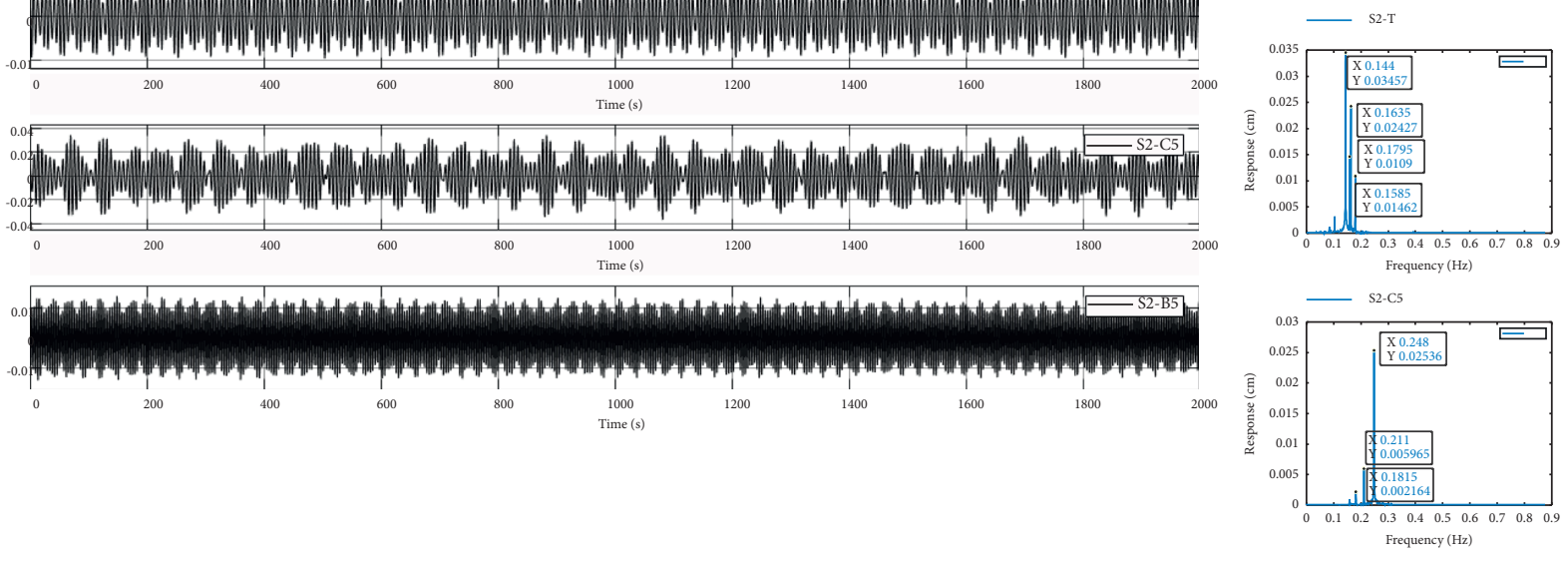

(b)

Figure 12: Continued. 

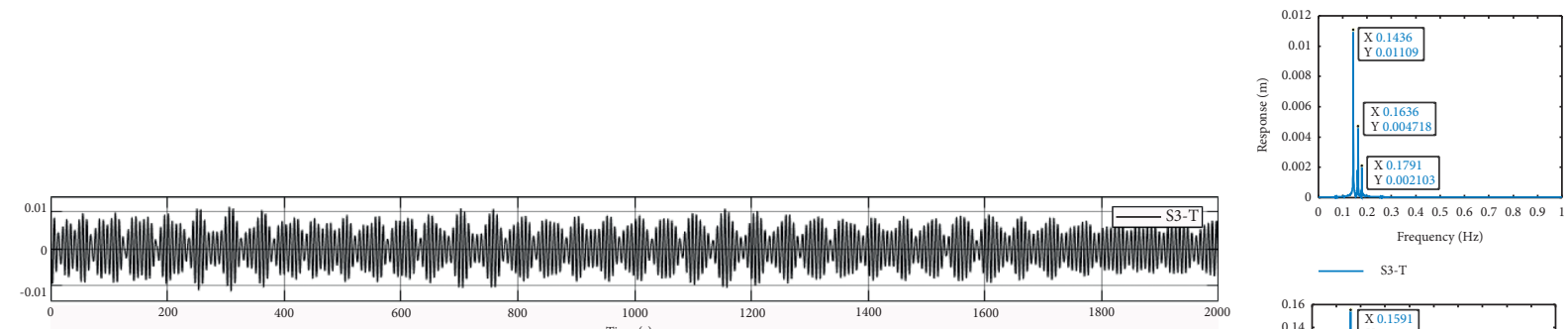

Frequency $(\mathrm{Hz})$

- S3-T
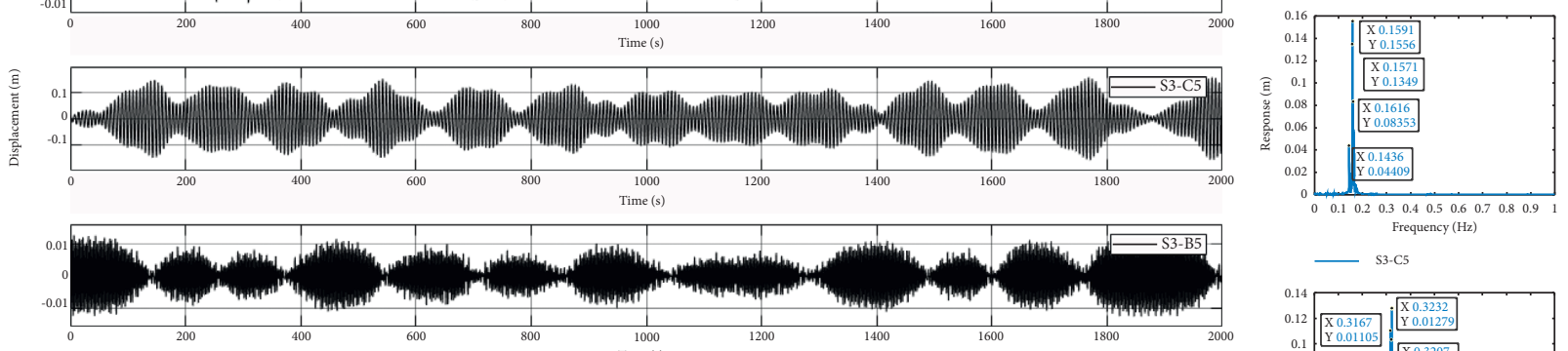

(c)
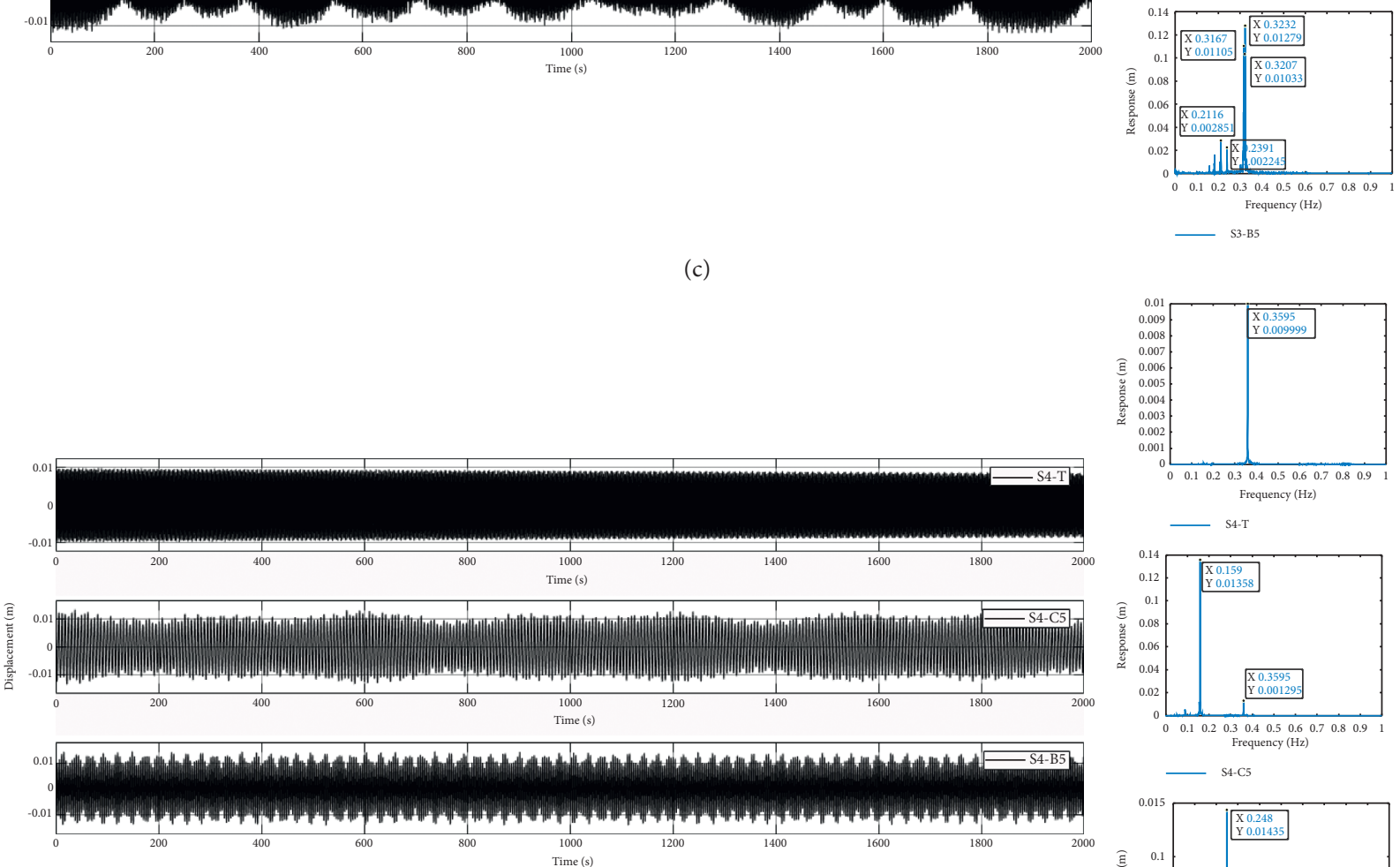

— $53-\mathrm{B} 5$

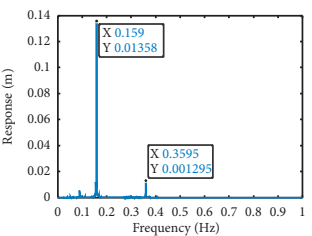

- $54-\mathrm{C} 5$

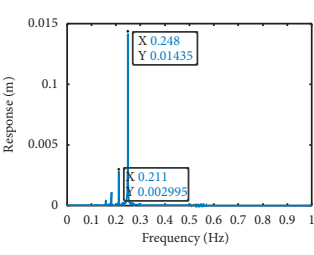

— S4-B

(d)

FIGURE 12: The spectrograms of each component under different working conditions. (a) Under $S_{1}$ condition, the spectrograms of the tower, cable, and beam in the $C_{5}$ subsystem. (b) Under $S_{2}$ condition, the spectrograms of the tower, cable, and beam in the $C_{5}$ subsystem. (c) Under $S_{3}$ condition, the spectrograms of the tower, cable, and beam in the $C_{5}$ subsystem. (d) Under $S_{4}$ condition, the spectrograms of the tower, cable, and beam in the $C_{5}$ subsystem. 

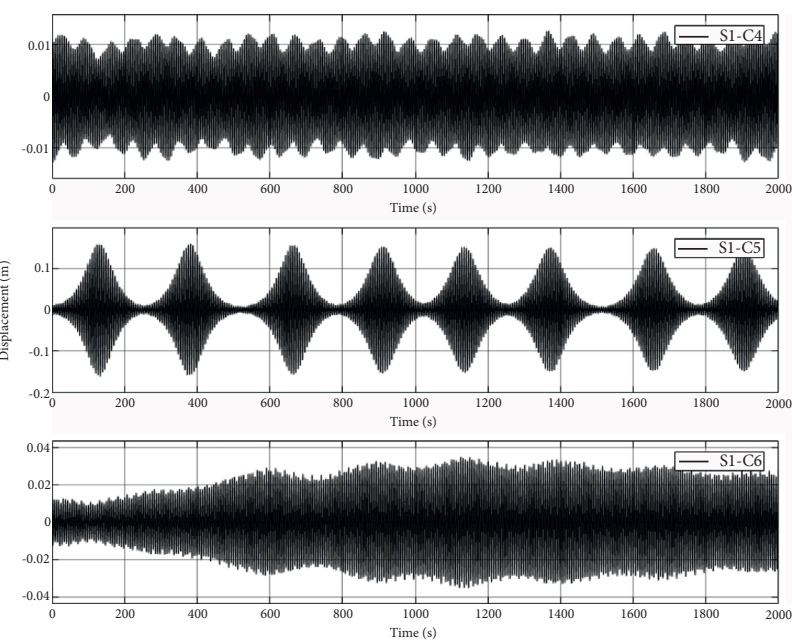

(a)
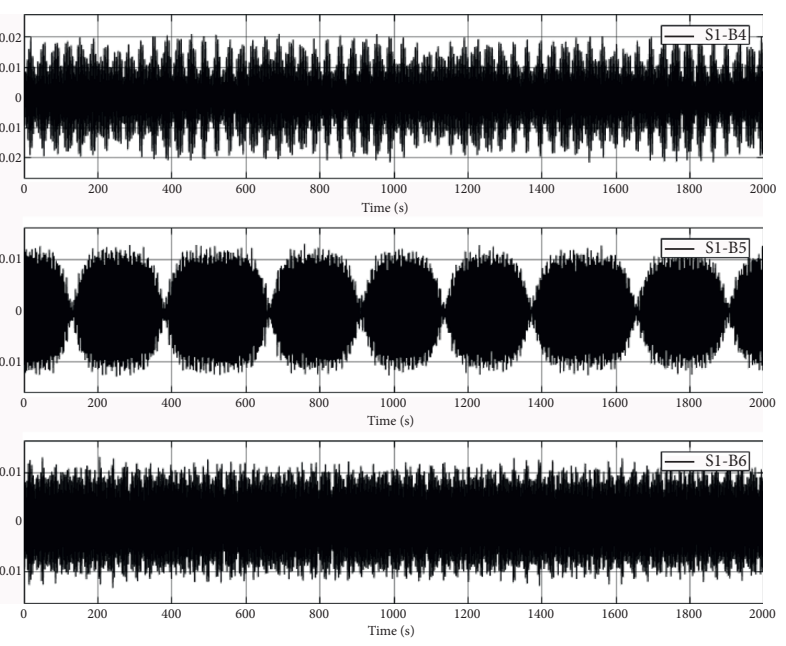

.

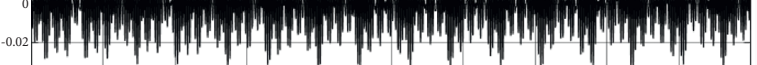

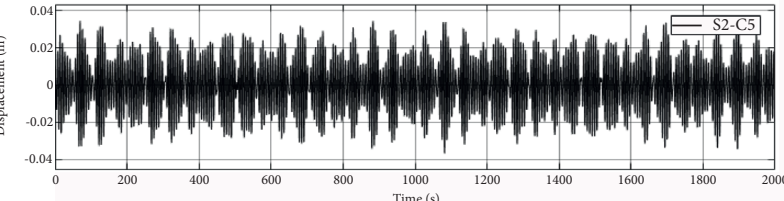

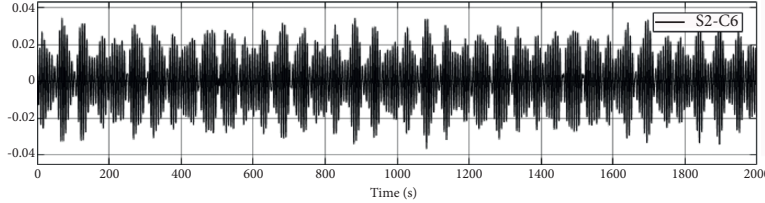

(b)

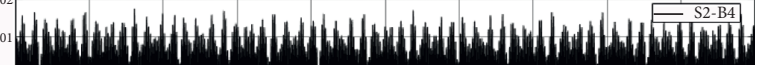

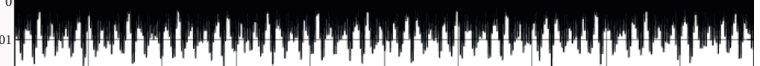

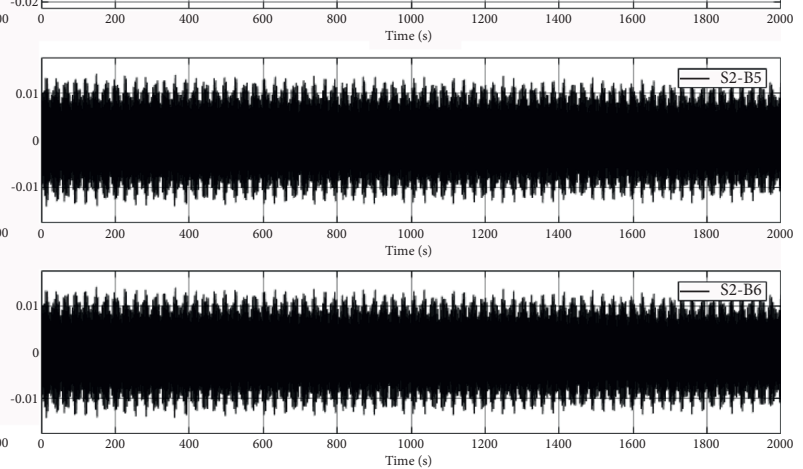

$\underbrace{0.04}_{0.00}$

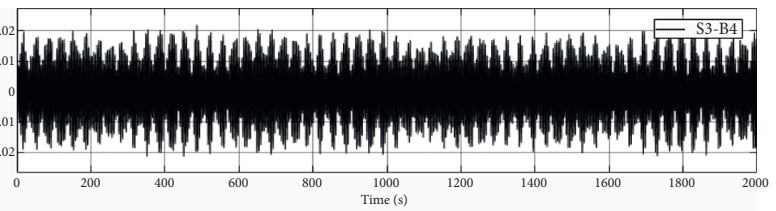
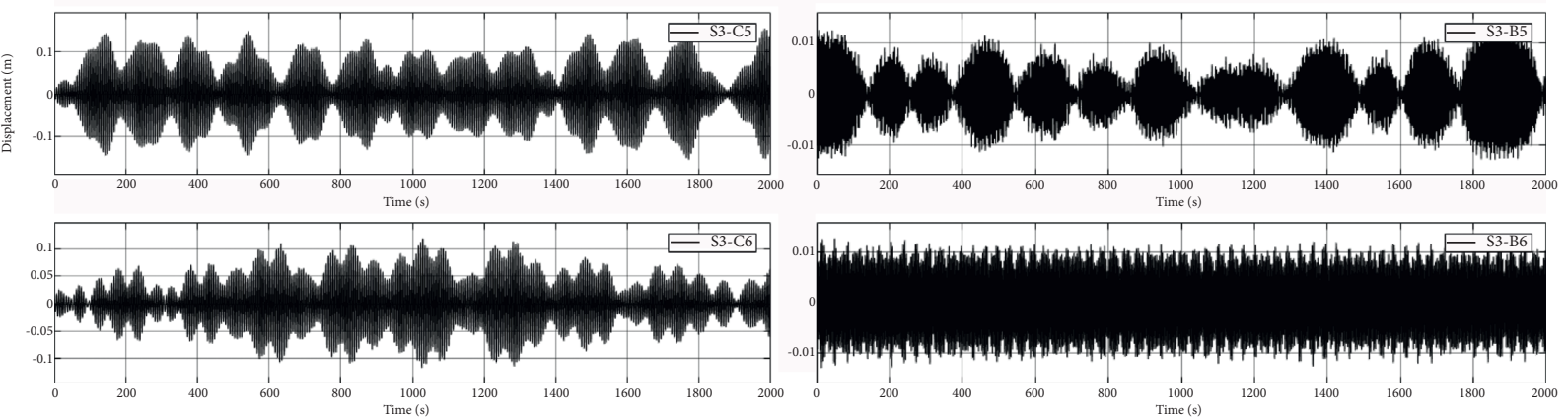

(c)

Figure 13: Continued. 

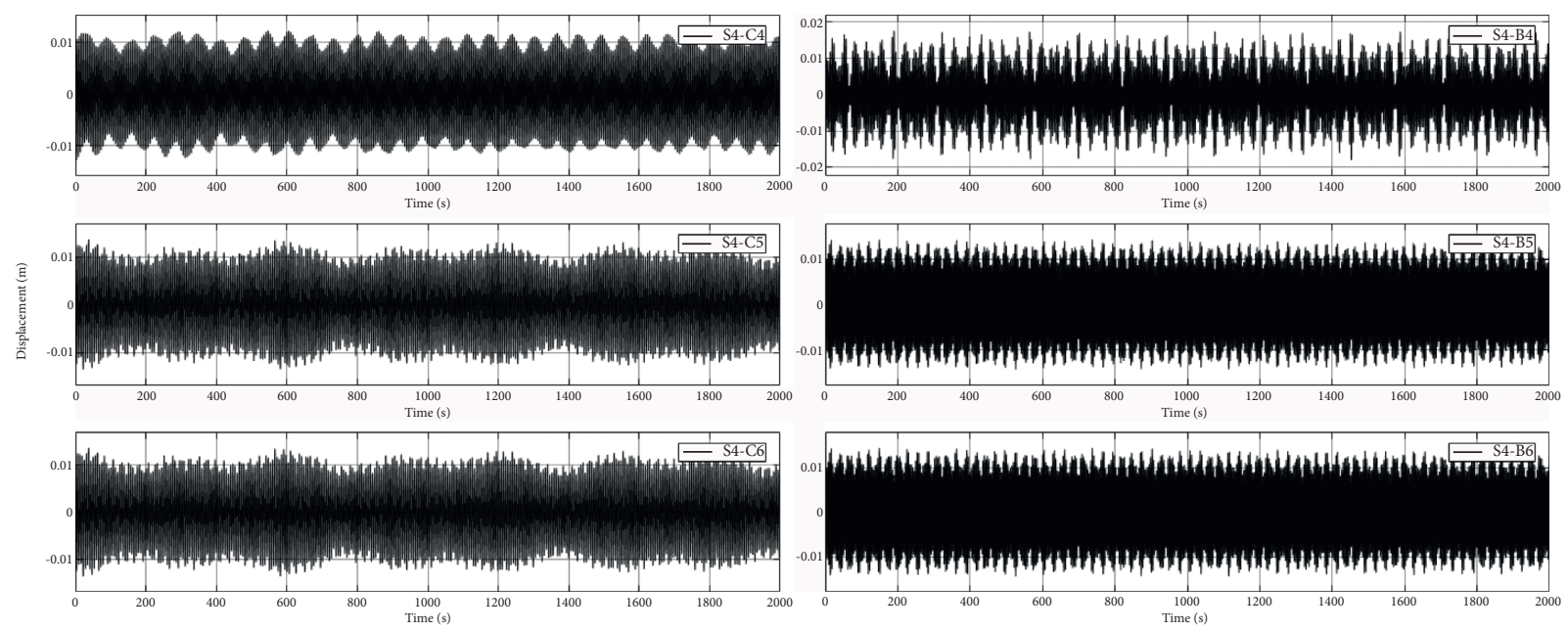

(d)

Figure 13: The response of the cable and beam in the $C_{4} \sim C_{6}$ subsystem under $S_{1} \sim S_{4}$ working conditions. (a) Under $S_{1}$ condition, the resonance response of the cable and beam in the $C_{4} \sim C_{6}$ subsystem. (b) Under $S_{2}$ condition, the resonance response of the cable and beam in the $C_{4} \sim C_{6}$ subsystem. (c) Under $S_{3}$ condition, the resonance response of the cable and beam in the $C_{4} \sim C_{6}$ subsystem. (d) Under $S_{4}$ condition, the resonance response of the cable and beam in the $C_{4} \sim C_{6}$ subsystem.

TABLE 6: The maximum displacement values of the beam portion under various working conditions.

\begin{tabular}{|c|c|c|c|c|}
\hline \multirow{2}{*}{ Abbreviation } & \multicolumn{4}{|c|}{ The maximum displacement response values of the beam portion $(\mathrm{mm})$} \\
\hline & $S_{1}$ & $S_{2}$ & $S_{3}$ & $S_{4}$ \\
\hline$B_{1}$ & 10.23 & 10.00 & 10.15 & 10.16 \\
\hline$B_{2}$ & 14.26 & 14.24 & 14.15 & 14.35 \\
\hline$B_{3}$ & 18.39 & 17.99 & 18.31 & 18.22 \\
\hline$B_{4}$ & 17.44 & 17.53 & 17.24 & 17.75 \\
\hline$B_{5}$ & 11.21 & 14.15 & 10.73 & 14.41 \\
\hline$B_{6}$ & 11.21 & 14.15 & 10.73 & 14.41 \\
\hline$B_{7}$ & 17.45 & 17.53 & 17.23 & 17.76 \\
\hline$B_{8}$ & 18.38 & 17.99 & 18.31 & 18.22 \\
\hline$B_{9}$ & 14.25 & 14.24 & 14.14 & 14.37 \\
\hline$B_{10}$ & 10.23 & 10.00 & 10.14 & 10.16 \\
\hline
\end{tabular}

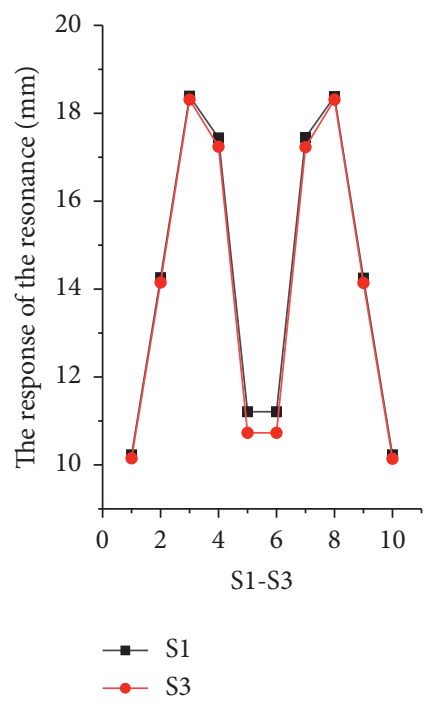

(a)

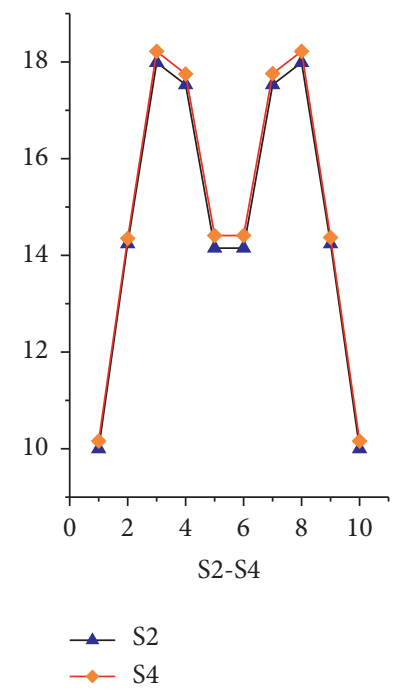

(b)

FIGURE 14: The difference of resonance response under comparison working conditions. 


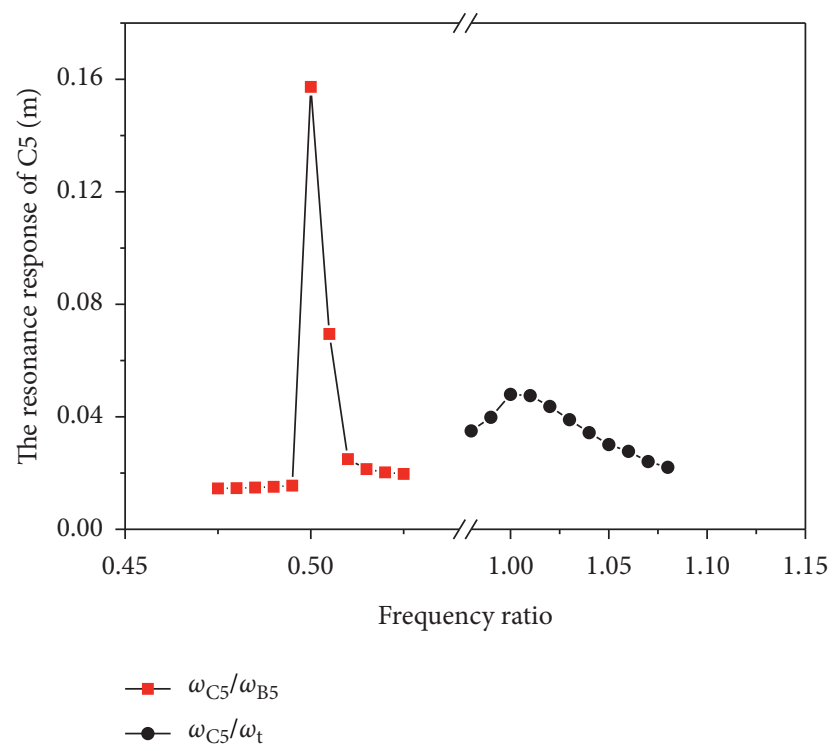

FIGURE 15: The relationship between frequency ratio and the maximum response of $C_{5}$.

efficient to change the vibration frequency value of a single cable, and more consideration should be given to the tower parameter frequency value being far away from the resonance interval in the design. However, the tower is directly connected to the cables of each subsystem, resulting in that the system energy is converted between the various subsystems when parametric occurs. Therefore, the maximum amplitude of the cable-tower resonance may not increase too large.

\section{Conclusion}

This paper proposes a refined model to analyze the parametric resonance phenomena in multicable systems, such as cable-stayed bridges, accounting for the interaction between adjacent beam portions. The comparison results between the finite method, the reference results, and this paper indicate the refined model exhibits the key character of parametric resonance and also further verified the simulation methods.

The consequences of the numerical simulation show that the cable has a severe resonance when the vibration frequency ratio of cable to the end horizontal excitation in the tower is $1: 1$, or that of cable and end orthogonal excitation in the beam is $1: 2$. Additionally, the beam portions within the two adjacent subsystems are stimulated by the global resonance, causing a gradual increase in the vibration response of the beam portion and the connected cable. However, if the coupling resonance conditions in the two adjacent subsystems are not satisfied, the beam excitation from the adjacent subsystems could not, therefore, be responsible for the severe cable resonance. Concisely, the local resonance will not lead to the global resonance when parametric resonance occurs in this subsystem, while the global resonance will have an effective excitation on the local resonance of this target subsystem which satisfies the resonance condition. Moreover, the probability of cable-beam coupling resonance occurrence is smaller than that of tower- cable coupling resonance. Therefore, more attention should be paid to avoid cable-tower resonance in the design of bridges engineering.

In the present study, the analysis of parameter sensitivity and resonance quantization precision (such as the sag and the gravity of the cable) is not comprehensive. Further studies involving a more detailed analysis of these aspects are expected to carry on at the next stage of the investigation to guide engineering practice.

\section{Data Availability}

The data of this study are available from the corresponding author upon request.

\section{Conflicts of Interest}

The authors declare that they have no conflicts of interest.

\section{Acknowledgments}

Financial supports from Natural Science Foundation of Shaanxi Province (no. 2021JM-174) and Fundamental Research Business Fees of Central Universities of Chang'an University (no. 310821161012) are gratefully acknowledged.

\section{References}

[1] H. J. Kang, Y. Y. Zhao, and L. Z. Jiang, "In-plane nonlinear vibration of super long stay cables under parametric and forced excitations," Journal of Central South University, vol. 42, no. 8, pp. 2439-2445, 2011.

[2] S. Kumarasena, N. P. Jones, P. Irwin, and T. Peter, "WindInduced vibration of stay cables [final report; August 2007]," Technical Report, National Transportation Library No. FHWA-RD-05-083, Washington. DC, USA, 2007.

[3] M. Matsumoto, "Vortex-induced vibration of inclined cables at high wind velocity, Wind Engineering into the 21st Century," in Proceedings of the Tenth International Conference on 
Wind Engineering, pp. 979-986, Copenhagen, Denmark, June 1999.

[4] J. A. Main and N. P. Jones, "Full-scale measurements of stay cable vibration," in Proceedings of the 10th International Conference on Wind Engineering (10ICWE). Wind Engineering into the 21st Century, pp. 963-970, Copenhagen Denmark, June 1999.

[5] H. Tabatabai and A. B. Mehrabi, "Vibration suppression measures for stay cables," in Proceedings of the 17 th International Modal Analysis Conference, Society for Experimental Mechanics, Inc, Kissimmee Florida, February 1999.

[6] B. Weber, "Nonlinear stay cable-bridge deck interaction," in Proceedings of the International Conference on Experimental Vibration Analysis for Civil Engineering Structures, pp. 902913, San Diego, CA, USA, 2017.

[7] Y. L. Yu, W. C. Gao, and Y. Sun, "Study on the refined vibration model of cable parameters and its influencing factors," Engineering Mechanics, vol. 27, no. s2, pp. 178-185, 2010.

[8] H. M. Irvine, Cable Structure (Structural Mechanics), The MIT Press, Cambridge, MA, USA, 1981.

[9] K. Zhan and W. X. Zhong, "Numerical study on parametric resonance of cables in cable stayed bridges," China Civil Engineering Journal, vol. 31, no. 4, pp. 14-22, 1998.

[10] S. S. Chen and B. N. Sun, "Numerical study on nonlinear parametric vibration of coupled cables and bridge decks," China Civil Engineering Journal, vol. 36, no. 4, pp. 70-75, 2003.

[11] C. Tan, Vibration of Cable Parameters and Finite Element Analysis of Cable-Stayed Bridge, Southwest Jiaotong University, Chengdu, China, 2006.

[12] F. Wang, F. Q. Chen, and X. X. Wen, "Analysis of cable parametric vibration model and response with consideration of temperature effect," Journal of Chongqing Jianzhu University, vol. 35, no. 2, 2016.

[13] F. Wang, Z. Peng, and H. R. Li, "Analysis on pylon-cablegirder coupled vibration model and influence considering temperature effect," Journal of Highway and Transportation Research and Development, vol. 35, no. 11, pp. 51-60, 2018.

[14] Y. Y. Cong, H. J. Kang, T. D. Guo, X. Su, and Y. Jin, “A multiple cable-beam model and modal analysis on in-plane free vibration of cable-stayed bridge with CFRP cables," Journal of Dynamics and Control, vol. 15, no. 6, pp. 494-504, 2017.

[15] Y. B. Yang and J. Y. Tsay, “Two-node catenary cable element with rigid-end effect and cable shape analysis," International Journal of Structural Stability and Dynamics, vol. 11, no. 3, pp. 563-580, 2011.

[16] H. J. Kang, H. P. Zhu, Y. Y. Zhao, and Z. P. Yi, "In-plane nonlinear dynamics of the stay cables," Nonlinear Dynamics, vol. 73, no. 3, pp. 1385-1398, 2013.

[17] C. S. Sun, T. B. Zhao, and H. J. Kang, "Multiple internal resonances and coupling process of cable-stayed bridge," Journal of Vibration and Shock, vol. 37, no. 10, pp. 87-93, 2018.

[18] J. H. G. Macdonald, "Multi-modal vibration amplitudes of taut inclined cables due to direct and/or parametric excitation," Journal of Sound and Vibration, vol. 363, pp. 473-494, 2016.

[19] C. Sun, Y. Zhao, J. Peng, H. Kang, and Y. Zhao, "Multiple internal resonances and modal interaction processes of a cable-stayed bridge physical model subjected to an invariant single-excitation," Engineering Structures, vol. 172, pp. 938955, 2018.
[20] M. H. El Ouni, N. Ben Kahla, and A. Preumont, "Numerical and experimental dynamic analysis and control of a cable stayed bridge under parametric excitation," Engineering Structures, vol. 45, pp. 244-256, 2012.

[21] E. Caetano, A. Cunha, V. Gattulli, and M. Lepidi, "Cable-deck dynamic interactions at the International Guadiana Bridge: on-site measurements and finite element modelling," Structural Control and Health Monitoring, vol. 15, no. 3, pp. 237-264, 2008.

[22] Y. Cong and H. Kang, "Planar nonlinear dynamic behavior of A cable-stayed bridge under excitation of tower motion," European Journal of Mechanics-A: Solids, vol. 76, pp. 91-107, 2019.

[23] Y. Cong, H. Kang, and T. Guo, "Planar multimodal 1:2:2 internal resonance analysis of cable-stayed bridge," $\mathrm{Me}$ chanical Systems and Signal Processing, vol. 120, no. 1, pp. 505-523, 2019.

[24] V. Gattulli and M. Lepidi, "Localization and veering in the dynamics of cable-stayed bridges," Computers \& Structures, vol. 85, no. 21-22, pp. 1661-1678, 2007.

[25] G. Ricciardi and F. Saitta, "A continuous vibration analysis model for cables with sag and bending stiffness," Engineering Structures, vol. 30, no. 5, pp. 1459-1472, 2008.

[26] C. J. Tan and B. Zhu, "Coupled vibration analysis of bridge deck and cable of long-span cable-stayed bridge," Journal of Southwest Jiaotong University, vol. 42, no. 6, pp. 726-731, 2007.

[27] X. Su, H. Kang, and T. Guo, "Modelling and energy transfer in the coupled nonlinear response of a 1:1 internally resonant cable system with a tuned mass damper," Mechanical Systems and Signal Processing, vol. 162, Article ID 108058, 2022.

[28] M. H. E. Ouni and N. B. Kahla, "Numerical study of the active tendon control of a cable-stayed bridge in a construction phase," Shock and Vibration, vol. 2014, Article ID 937541, 10 pages, 2014.

[29] T. Wang, R. L. Shen, and H. Li, "Primary exploration for concept and studying method of cable- beam vibration in a cable stayed bridge," Journal of Vibration and Shock, vol. 32, no. 20, pp. 29-34, 2013.

[30] H. J. Fang, X. Y. Wang, and Y. F. Luo, "FEM analysis and experimental study on planar parametric oscillations of the stayed cable," Chinese Journal of Applied Mechanics, vol. 36, no. 02, pp. 438-514, 2019.

[31] Y. Y. Yang and K. J. Chen, "Research on parametric oscillation of cables for long span railway cable -stayed bridge," Journal of Railway Engineering Society, vol. 169, no. 10, pp. 60-65+91, 2013.

[32] V. Gattulli, M. Lepidi, J. H. G. Macdonald, and C. A. Taylor, "One-to-two global-local interaction in a cable-stayed beam observed through analytical, finite element and experimental models," International Journal of Non-linear Mechanics, vol. 40, no. 4, pp. 571-588, 2005.

[33] H. T. Liu, M. H. Wei, and Y. Q. Xiao, "Nonlinear response analysis of a cable-beam coupled system," Journal of Vibration and Shock, vol. 34, no. 14, pp. 147-152+182, 2015.

[34] H. J. Kang, T. D. Guo, Y. Y. Zhao, W. B. Fu, and L. H. Wang, "Dynamic modeling and in-plane 1:1:1 internal resonance analysis of cable-stayed bridge," European Journal of Mechanics - A: Solids, vol. 62, pp. 94-109, 2017.

[35] Y. Cong, H. Kang, and T. Guo, "Analysis of in-plane 1:1:1 internal resonance of a double cable-stayed shallow arch model with cables' external excitations," Applied Mathematics and Mechanics, vol. 40, no. 7, pp. 977-1000, 2019. 
[36] W. J. Zhang, B. Wang, and J. B. Yang, "Study of vibration property of stay cables of Jiujiang Changjiang river highway bridge," World Bridges, vol. 40, no. 6, pp. 47-51, 2012.

[37] Z. X. Wang, B. Wang, and X. P. Chai, "Research advancement of damping techniques for stay cables of long span cablestayed bridges," Bridge Construction, vol. 45, no. 3, pp. 13-19, 2015.

[38] Z. Wu and J. Wei, "Nonlinear analysis of spatial cable of longspan cable-stayed bridge considering rigid connection," KSCE Journal of Civil Engineering, vol. 23, no. 5, pp. 2148-2157, 2019.

[39] Y. Y. Zhao, T. Wang, and H. J. Kang, "Performance study of the nonlinear parametric vibration of coupled bridge decks and two cables," Journal of Hunan University, vol. 35, no. 10, pp. 1-5, 2008.

[40] H. J. Kang, T. D. Guo, and Y. Y. Zhao, "Review on nonlinear vibration and modeling of large span cable-stayed bridge," Chinese Journal of Theoretical and Applied Mechanics, vol. 48, no. 3, pp. 519-535, 2016.

[41] M. Virlogeux, "Cable vibrations in cable-stayed bridges," in Bridge Aerodynamics, A. Larsen and S. Esdahl, Eds., pp. 213-233, A. A. Balkema, Rotterdam, Netherlands, 1998.

[42] Y. Zhang, H. Wang, and J. Yang, "Dynamics of a three degrees of freedom nonlinear vibration model of cables and bridge decks and towers with the frequency 1:2:1 internal resonance," Journal of Dynamics and Control, vol. 8, no. 1, pp. 62-66, 2010. 